ARTICLE

DOI: $10.1038 / \mathrm{s} 41467-018-05928-5$

\title{
Structural basis for importin alpha 3 specificity of W proteins in Hendra and Nipah viruses
}

Kate M. Smith', Sofiya Tsimbalyuk, Megan R. Edwards², Emily M. Cross', Jyoti Batra², Tatiana P. Soares da Costa ${ }^{3}$, David Aragão (1) ${ }^{4}$, Christopher F. Basler (1) ${ }^{2}$ \& Jade K. Forwood

Seven human isoforms of importin $\alpha$ mediate nuclear import of cargo in a tissue- and isoform-specific manner. How nuclear import adaptors differentially interact with cargo harbouring the same nuclear localisation signal (NLS) remains poorly understood, as the NLS recognition region is highly conserved. Here, we provide a structural basis for the nuclear import specificity of $\mathrm{W}$ proteins in Hendra and Nipah viruses. We determine the structural interfaces of these cargo bound to importin $\alpha 1$ and $\alpha 3$, identifying a 2.4-fold more extensive interface and $>50$-fold higher binding affinity for importin $\alpha 3$. Through the design of importin $\alpha 1$ and $\alpha 3$ chimeric and mutant proteins, together with structures of cargo-free importin $\alpha 1$ and $\alpha 3$ isoforms, we establish that the molecular basis of specificity resides in the differential positioning of the armadillo repeats 7 and 8 . Overall, our study provides mechanistic insights into a range of important nucleocytoplasmic transport processes reliant on isoform adaptor specificity.

\footnotetext{
${ }^{1}$ School of Biomedical Sciences, Charles Sturt University, Wagga Wagga, NSW 2678, Australia. ${ }^{2}$ Center for Microbial Pathogenesis, Institute for Biomedica Sciences, Georgia State University, Atlanta, GA 30303, USA. ${ }^{3}$ Department of Biochemistry and Genetics, La Trobe Institute for Molecular Science, La Trobe University, Melbourne, VIC 3086, Australia. ${ }^{4}$ Australian Synchrotron, Australian Nuclear Science and Technology Organisation, 800 Blackburn Road, Clayton, VIC 3168, Australia. These authors contributed equally: Kate M. Smith, Sofiya Tsimbalyuk, Megan R. Edwards. These authors jointly supervised this work: Christopher F. Basler, Jade K. Forwood. Correspondence and requests for materials should be addressed to C.F.B. (email: cbasler@gsu.edu) or to J.K.F. (email: jforwood@csu.edu.au)
} 
A ctive transport of proteins from the cytoplasm to the nucleus is mediated by a family of nuclear transport receptors known as importins (or karyopherins), together with a number of ancillary proteins including nucleoporins and $\operatorname{Ran}^{1-3}$. The classical nuclear import pathway is best understood, and is initiated by recognition of proteins that contain a classical nuclear localisation sequence (NLS) by importin $\alpha^{4}$. This complex is transported through the nuclear pore complex by importin $\beta$, involving interactions with FG repeat regions contained within nucleoporin proteins 5,6 . Once the complex has traversed the nuclear envelope, RanGTP dissociates the complex, and the import receptors are recycled back to the cytoplasm to perform further rounds of transport ${ }^{7-10}$. Importin $\alpha$ is constructed from an $\mathrm{N}$-terminal importin $\beta$-binding (IBB) domain and a Cterminal NLS binding domain featuring ten armadillo (ARM)repeat motifs ${ }^{11}$. Most commonly, the cargo NLS binds on the concave site of the ARM repeats and involves interactions at either the major site, through ARM repeats 2-4 in the case of classical monopartite NLSs (e.g., SV40T-ag ${ }^{12}$ ), the minor site involving ARM repeats 6-8 (e.g., human phospholipid scramblase $^{13}, \mathrm{TPX} 2^{14}$ ) or both the major and minor sites in the case of classical bipartite NLSs (e.g., nucleoplasmin ${ }^{12}$ ). Although this process has been well characterised for the importin $\alpha 1$ adaptor protein, many nuclear proteins exhibit specificity for other importin $\alpha$ isoforms, and the molecular basis for this specificity is understood poorly. Complicating our understanding of how importin a isoforms exhibit specificity, the seven importin a isoforms are highly conserved in the regions that mediate NLS binding. Establishing how nuclear cargo are recognised in an isoform-specific manner is important for understanding many key regulatory processes including cell differentiation, cancer and viral infection. For example, both RCC1 (the exchange factor of Ran that regulates the directionality of nuclear transport) and HIV-1 integrase (responsible for integrating the HIV-1 genome into the DNA of an infected cell) bind specifically to importin $\alpha 3^{15,16}$. STAT1, a signalling molecule in the innate immune system response, binds specifically to the convex C-terminal surface of importin $\alpha 5, \alpha 6$ and $\alpha 7^{17,18}$. The avian influenza PB2 viral polymerase subunit, which is a major virulence determinant, has isoform specificity for importin $\alpha 3$ in avian hosts and importin $\alpha 7$ in mammalian hosts, providing a kinetic advantage owing to lower importin $a$ autoinhibition by the importin beta binding domain ${ }^{19}$.

The $\mathrm{W}$ protein of Nipah virus $(\mathrm{NiV})$ is recognised specifically by importin $\alpha 3$, which occurs through an NLS in the unique Cterminal domain ${ }^{20,21}$, however, the basis of this specificity remains unclear. $\mathrm{HeV}$ and $\mathrm{NiV}$ are recently emergent, zoonotic pathogens of the Henipavirus genus in the Paramyxoviridae family. These viruses use bats of the Pteropus genus as reservoir hosts but cause infections in humans with a high rate of fatality $(\sim 60 \%)^{22}$. The viruses are non-segmented, negative-sense RNA viruses and encode six genes, five of which encode a single protein, whereas, the sixth gene, $\mathrm{P}$, encodes four proteins: $\mathrm{P}, \mathrm{V}, \mathrm{W}$ and $\mathrm{C}$. Of these, $\mathrm{P}, \mathrm{V}$ and $\mathrm{W}$ share a common $\mathrm{N}$-terminal domain, but differ within the C-terminal domain owing to frameshifting that results from insertion of non-template encoded nucleotides into $\mathrm{P}$ gene transcripts ${ }^{23-25}$. This results in proteins that have different functions and cellular locations, with only the $\mathrm{W}$ protein displaying steady-state nuclear localisation owing to a C-terminally located $\mathrm{NLS}^{20,26}$. In the context of NiV infection, the nonstructural $\mathrm{W}$ protein plays an important role in virulence ${ }^{27-29}$. It has been demonstrated to antagonise innate antiviral defences by blocking interferon-induced gene expression and by preventing expression of type I IFNs, with nuclear localisation shown to be important for the latter function ${ }^{20,30}$. A recent study has identified additional host targets of $\mathrm{NiV} \mathrm{W}$, including the PRP19 complex, for which the nuclear localisation of $\mathrm{W}$ appears to be required for the interaction ${ }^{31}$.

Previous reports have demonstrated specificity of the importin a3 adaptor for the NiV W protein, however, like most cargo, the basis for this specificity is unknown ${ }^{20,32}$. Here, we establish key differences in the binding interface of $\mathrm{W}$ proteins with importin $\alpha 1$ and a3, providing insights into adaptor specificity. We use mutagenesis and chimeras of importin $\alpha 1$ and $\alpha 3$ to confirm the importance of these differences and show that the C-terminal ARM repeats 7 and 8 of importin $\alpha 3$ are important for specificity as their conformation in importin $\alpha 3$ allows for an extensive binding interface not possible in importin a1. These insights extend our understanding of adaptor specificity and establish how important nuclear cargo proteins are imported in an isoform-specific manner.

\section{Results}

Henipavirus $W$ preferentially bind importin $\alpha 3$ and $\alpha 4$. The $W$ proteins of henipaviruses share a common N-terminal domain with $\mathrm{P}$ and $\mathrm{V}$ proteins, but have a unique NLS bearing C-terminal domain that is recognised preferentially by importins $\alpha 3$ and $\alpha 4$ (KPNA4 and KPNA3), rather than the better characterised importin a1 (KPNA2) (Fig. 1a and Supplementary Fig. 1A) ${ }^{20}$. To confirm this, and assess $\mathrm{W}$ binding against a more extensive range of importin a isoforms, we performed coimmunoprecipitation assays against respective importins and probed for the presence of $\mathrm{HeV}$ and $\mathrm{NiV}$ W. We found that both $\mathrm{HeV}$ and NiV W bound preferentially to importin $\alpha 3$ and $\alpha 4$, but not importin $\alpha 1, \alpha 5, \alpha 6$ or $\alpha 7$ (Fig. 1b and Supplementary Fig. 2). These importin as extend across all subfamilies (Supplementary Fig. 1B), confirming that the $\mathrm{W}$ protein binds specifically to members of importin a subfamily- 2 .

To determine the binding affinities between importin $\alpha 3$ and Henipavirus W proteins, as well as confirm a direct interaction, the C-terminal NLS domain of the $\mathrm{W}$ protein from both $\mathrm{HeV}$ and $\mathrm{NiV}$ were cloned as a glutathione S-transferases (GST) fusion protein and assessed for importin a binding by isoforms from representative subfamilies. From enzyme-linked immunosorbent assay (ELISA) measurements, we found that importin $\alpha 3$ bound with high affinity to the $\mathrm{W}$ protein from both $\mathrm{HeV}$ and $\mathrm{NiV}(19.9$ $\mathrm{nM}$ and $14.4 \mathrm{nM}$, respectively), whereas importin $\alpha 1$ and $\alpha 7$ bound with much lower affinity $(1.4 \mu \mathrm{M}$ and $1.5 \mu \mathrm{M}$, respectively, to $\mathrm{HeV} \mathrm{W}$; and $1.5 \mu \mathrm{M}$ and $1.1 \mu \mathrm{M}$, respectively, to $\mathrm{NiV} \mathrm{W}$ ) (Fig. 1c; Supplementary Table 1). We found comparable binding using microscale thermophoresis (MST) assays, with importin a3 binding $\mathrm{NiV} \mathrm{W}$ protein with high affinity $(4.4 \mathrm{nM})$, whereas importin $\alpha 1$ and $\alpha 7$ displayed a much lower affinity (681 and 696 nM, respectively) (Fig. 1d; Supplementary Table 2). Together these data establish a direct, high-affinity interaction of the W proteins from henipaviruses for importin a 3 compared with other importin a subfamilies.

Structural basis for importin $\alpha$ isoform specificity to $W$. To establish the mechanism and molecular basis of the isoform-specific differences, we used X-ray crystallography to determine the structural interface of both the high-affinity importin $\alpha 3$ interaction and the low-affinity importin $\alpha 1$ interaction. Structures were determined for importin $\alpha 3$ and $\alpha 1$ bound to both the $\mathrm{HeV}$ W and NiV W Cterminal NLS-bearing domain (Fig. 2 and Fig. 3, respectively). Crystals of the importin $\alpha 1: \mathrm{HeV} \mathrm{W}$ complex had $\mathrm{P} 2{ }_{1} 2_{1} 2_{1}$ symmetry and diffracted to $2.2 \AA$ resolution. The asymmetric unit (ASU) contained one importin al chain bound to a single $\mathrm{HeV}$ W chain, in which residues $434-441$ were bound to importin a1. The interaction was mediated by 15 hydrogen bonds, one salt bridge interaction, and buried a surface area of $683.5 \AA^{2}$ (see Table 1 for full 
a

\begin{tabular}{ll|l|l|l|}
\hline Woyouz & & Paramyxo_PCT & NLS \\
\hline 5 & 5271 & 381409 & 448
\end{tabular}

HeV W ${ }^{409}$ RSLNMLGRKTCLGRRVVQPGMFADYPPTKKARVLLRRMSN ${ }^{48}$ NiV W ${ }^{411}$ RNIHLLGRKTCLGRRVVQPGMFËDHPPTKKARV $\overline{\text { SMRRMSN }}{ }^{450}$

\section{b}

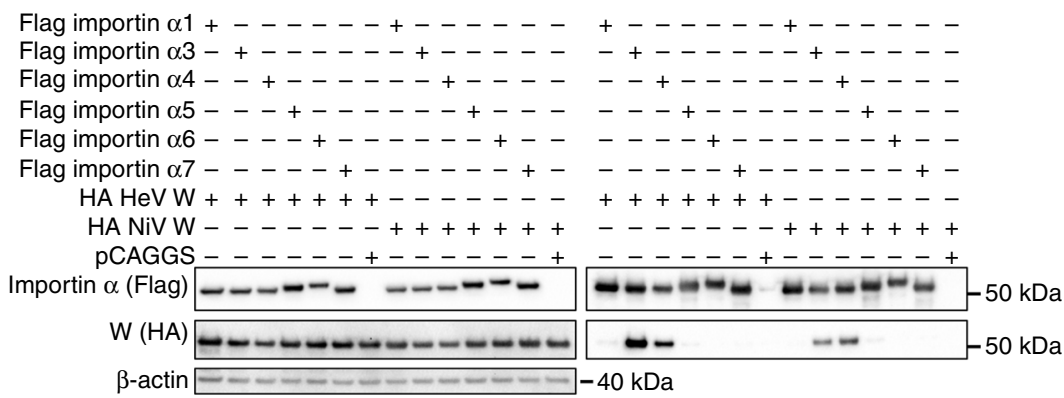

C

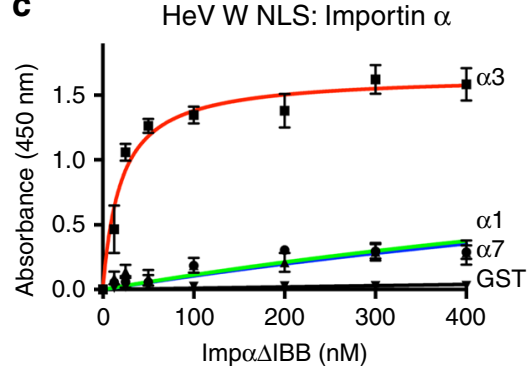

NiV W NLS: Importin $\alpha$

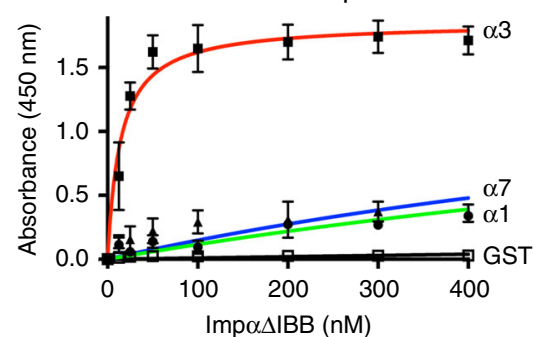

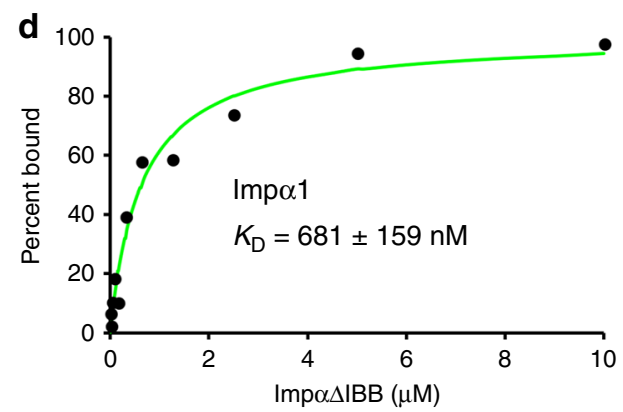
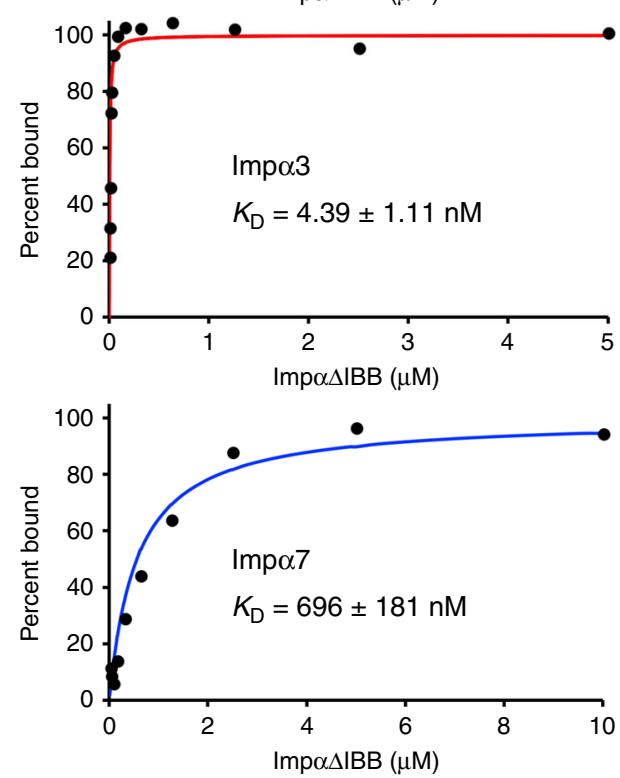

Fig. 1 Binding of Henipavirus W proteins to importins. The NLS regions of Henipavirus W proteins bind with high affinity and specificity to the importin $\alpha 2$ subfamily containing importin $\alpha 3$ and $\alpha 4$. a The W proteins contain the Soyouz module moiety (Soyouz) and PCT disordered (Paramyxo_PCT) regions, which are conserved across paramyxovirus phosphoproteins. However, the $\mathrm{W}$ proteins of $\mathrm{HeV}$ and NiV W also possess a unique $\mathrm{C}$ terminus compared with other P gene products and contain an NLS that mediates translocation of W into the nucleus. $\mathbf{b} \mathrm{HeV}$ W and NiV W interact with importin $\alpha 3$ and $\alpha 4$. Co-immunoprecipitation assay performed with Flag antibody on lysates of HEK293T cells expressing Flag-tagged importin $\alpha 1, \alpha 3, \alpha 4, \alpha 5, \alpha 6, \alpha 7$ and $H A$ tagged full length HeV W and NiV W, as indicated. Western blots were performed for HA and Flag. WCL, whole cell lysate; IP, immunoprecipitation. pCAGGS denotes empty vector control. c The NLS region of HeV W and NiV W interact with high affinity to importin $\alpha 3$. An ELISA was performed using GST-W (GST as a negative control) proteins coated on 96 -well plates, and binding of $6 x$ His-tagged importin $\alpha 1, \alpha 3, \alpha 7$ assessed using an anti-6xHis HRP antibody. Error bars show the S.E.M for three replicates. $\mathbf{d}$ MST assay confirms high affinity binding of importin $\alpha 3$ to the NLS region of NiV W proteins, and comparatively lower affinity binding to importin $\alpha 1$ and $\alpha 7$

data collection and refinement statistics and Supplementary Table 3 for a detailed list of the interactions).

The structure of the importin $\alpha 3: \mathrm{HeV} \mathrm{W}$ complex was determined in three different space groups (Table 2), with all crystals exhibiting highly similar structures (r.m.s.d $<0.35$; Supplementary Fig. 3) and containing one $\mathrm{HeV}$ W NLS chain bound to a single importin a 3 chain (the highest resolution structure of $1.6 \AA$ will be used for further discussion and analysis). In contrast to the importin $\alpha 1: \mathrm{HeV} \mathrm{W}$ complex, importin $\alpha 3$ bound a more extensive region of the $\mathrm{HeV}$ W C-terminal domain NLS (residues 419-444) and showed a more extensive array of hydrogen bonds ( 31 vs 15), seven salt bridge interactions (7 vs 1 ), and a greater buried surface area (1616.9 vs $683.5 \AA^{2}$ ); (see Supplementary Table 4 and Supplementary Table 5 for a detailed list of interactions and summary comparisons, respectively).

To test whether the same binding patterns were present in the $\mathrm{NiV} \mathrm{W}$ protein, we examined the binding determinants of importin $\alpha: \mathrm{NiV} \mathrm{W}$ complexes using the same approach. We observed binding patterns that were very similar to those seen with $\mathrm{HeV}$ W for both importin $\alpha 1$ and $\alpha 3$ (Fig. 3). Crystals of the importin $\alpha 1$ :
NiV W complex (that had P $2{ }_{1} 2{ }_{1}{ }_{1}$ symmetry and diffracted to 2.1 $\AA$ resolution) bound residues $436-443$ of the NiV W C-terminal domain. In comparison, the importin $\alpha 3: \mathrm{NiV} \mathrm{W}$ complex had P12 1 symmetry, diffracted to $2.3 \AA$ resolution, and showed more extensive binding, with residues 421-446 bound to importin a3. The binding interface was also similar to $\mathrm{HeV} \mathrm{W}$, with the importin a1:NiV W complex mediated by 15 hydrogen bonds, one salt bridge interaction, and a buried surface area of $688.7 \AA^{2}$. The importin $a 3$ : $\mathrm{NiV} \mathrm{W}$ interface was mediated through 31 hydrogen bonds, seven salt bridge interactions, and buried $1591.8 \AA^{2}$ of surface area. These results indicate that the interaction of the henipavirus $\mathrm{W}$ proteins with importins is highly conserved.

Establishing the structural interface between importin $\alpha 1$ and a3 in both $\mathrm{HeV} \mathrm{W}$ and $\mathrm{NiV} \mathrm{W}$ highlighted key differences in importin recognition and gave insights into isoform specificity. Notably, despite binding the same region of $\mathrm{HeV} \mathrm{W}$ and $\mathrm{NiV} \mathrm{W}$, importin a3 exhibited a 2.4-fold more extensive interaction buried surface area than importin a1, with 16 additional hydrogen bonds, and six additional salt bridge interactions, consistent with its $>50$-fold higher affinity. Both $\mathrm{W}$ proteins 


\section{HeV W RSLNMLGRKTCLGRRVVQPGMFADYPPTKKARVLLRRMSN}
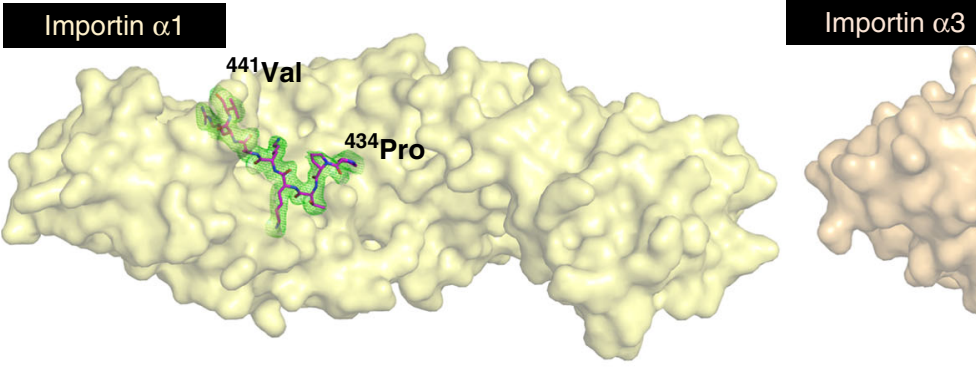

${ }^{444}$ Arg

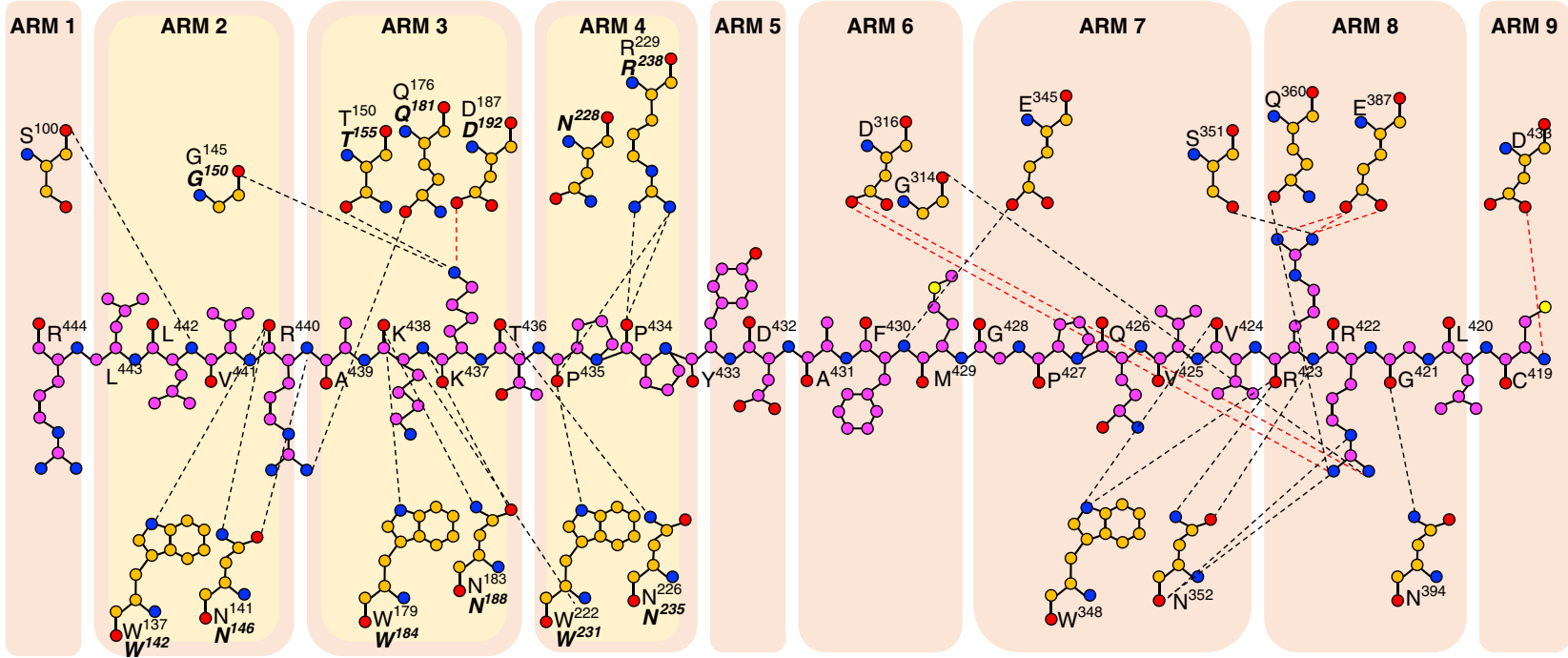

Fig. 2 Structural comparisons and basis for high affinity interaction of HeV W with importin $\alpha 3$. Importin $\alpha 1: \mathrm{HeV}$ W and importin $\alpha 3: \mathrm{HeV}$ W structures were solved to $2.2 \AA$ and $1.6 \AA$ resolution, respectively. The importin $\alpha$ adaptors are shown in cartoon and surface representation (importin $\alpha 1$ : bright yellow, importin $\alpha 3$ : light orange) and HeV W NLS in stick representation (magenta: carbon atoms, red: oxygen atoms, blue: nitrogen atoms) with associated simulated annealing Fo-Fc omit maps of the NLSs contoured to $3 \sigma$ in green. Schematics of the binding interface and specific interactions are shown below (magenta: carbon atoms, red: oxygen atoms, blue: nitrogen atoms), with hydrogen bond and salt bridge interactions depicted by dash lines (black and red respectively), and the partner interactions for importin $\alpha 1$ (bold italics) and importin $\alpha 3$ coloured as orange: carbon atoms, red: oxygen atoms, blue: nitrogen atoms. The location of these interactions in the ARM repeats highlight the greater interaction interface of the HeV W NLS for the importin $\alpha 3$ adaptor

interacted with the major binding site of importin $\alpha 1$ and $\alpha 3$, involving residues PPTKARV of $\mathrm{W}$ and ARM repeats $2-4$ of importin in both structures. However, there were marked differences residing outside this region, with importin a3 ARM repeats 6-9 binding $\mathrm{HeV} \mathrm{W}$ and $\mathrm{NiV} \mathrm{W}$ residues $419-444$ and 421-446, respectively (Figs. 2, 3). To probe the interaction of the importin a3:HeV W interface in greater detail, we designed mutations to disrupt key salt bridges at the major and minor sites of importin $\alpha 3$ (Fig. 4a). We found that mutations within the viral $\mathrm{W}$ proteins predicted to disrupt interactions at the minor site of importin a3 (specifically, R422A/R423A and R422D/R423D in the $\mathrm{HeV}$ W C-terminal domain and R424A/R425A and R424D/ $\mathrm{R} 425 \mathrm{D}$ in NiV W C-terminal domain) were no longer pulled down with importin $\alpha 3$ in our co-immunoprecipitation assay (Fig. 4b). Similarly, mutations predicted to disrupt interaction at the importin a 3 major site, K437A/K438A and K437D/K438D in $\mathrm{HeV}$ W C-terminal domain, and K439A/K440A and K439D/ $\mathrm{K} 440 \mathrm{D}$ in the $\mathrm{NiV} \mathrm{W}$ C-terminal domain, also failed to interact with importin a3. Consistent with these results, we found that mutations in both the major and minor site-binding regions of $\mathrm{HeV} \mathrm{W}$ disrupted the affinity of interaction to importin $\alpha 3$ in ELISA (Fig. 4c), and resulted in reduced nuclear accumulation (Fig. 4d, e). Overall, these results indicate that the binding of $\mathrm{W}$ to both the importin a major and minor sites is important for the high affinity interaction of henipavirus $\mathrm{W}$ to importin $a 3$.

ARMs 7 and 8 of importin $\alpha 3$ mediate isoform specificity. Our structural analysis of the $\mathrm{W}$ protein bound to importin $\alpha 1$ and a3 showed that all binding determinants on importin a3 are conserved in importin al (Fig. 5a and Supplementary Fig. 4), suggesting that isoform specificity is not due to differences in the NLS-binding groove. This is consistent with previous work by Pumroy et al. ${ }^{19}$. To gain insights into the basis of isoform specificity, we superimposed the structures of importin a1:HeV W and importin $a 3: \mathrm{HeV} \mathrm{W}$, and found the structures to be highly similar, with an r.m.s.d. of $1.1 \AA$ across 411 residues (Fig. 5b), except for the positioning of ARM repeats 7 and 8 . Notably, in importin $\alpha 1$, ARM repeats 7 and 8 are positioned closer to the inner surface of the NLS-binding interface, whereas in importin $\alpha 3$, these regions are positioned in a more open conformation. Because these ARM repeats provide a critical point of difference between the binding of importin $\alpha$ isoforms, we investigated why the W NLS region did not bind importin al in the extended 


\section{$\begin{array}{llllll}411 & 421 & 436 & 443 & 446 & 450\end{array}$ \\ NiV W RNIHLLGRTCLGRRVVPGMFEDHPPTKKARVSMRRMSN \\ Importin $\alpha 1$ \\ Importin $\alpha 3$}
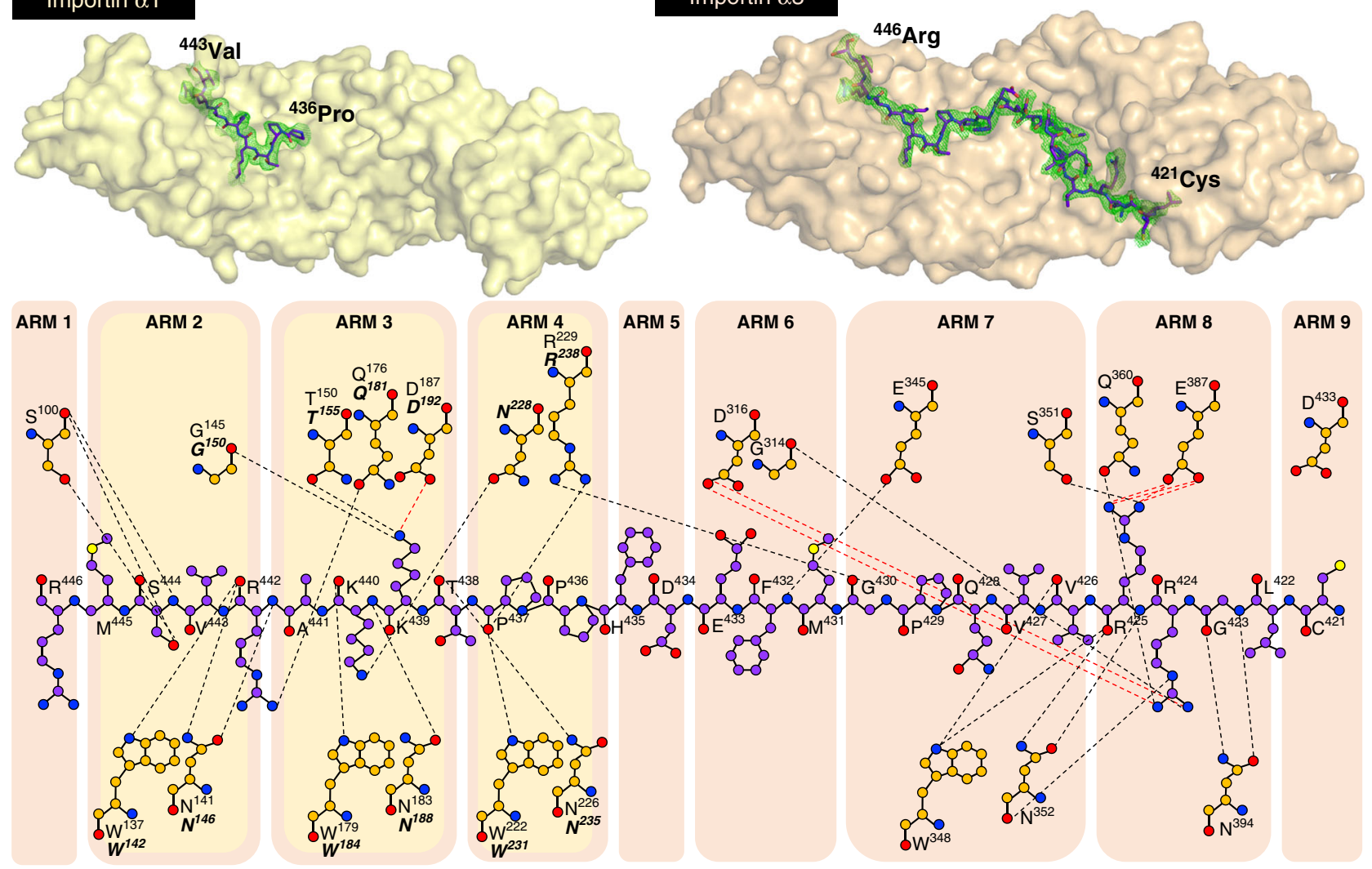

Fig. 3 Structural comparisons and basis for high-affinity interaction of NiV W with importin $\alpha 3$. Importin $\alpha 1$ :NiV W and importin $\alpha 3$ :NiV W structures were solved to $2.1 \AA$ and $2.3 \AA$ resolution, respectively. The importin $\alpha$ adaptors are shown in cartoon and surface representation (importin $\alpha 1$ : bright yellow, importin $\alpha 3$ : light orange) and NiV W NLS in stick representation (magenta: carbon atoms, red: oxygen atoms, blue: nitrogen atoms) with associated simulated annealing Fo-Fc omit maps of the NLSs contoured to $3 \sigma$ in green. Schematics of the binding interface and specific interactions are shown below (magenta: carbon atoms, red: oxygen atoms, blue: nitrogen atoms), with hydrogen bond and salt bridge interactions depicted by dash lines (black and red, respectively), and the partner interactions for importin $\alpha 1$ (bold italics) and importin $\alpha 3$ coloured as orange: carbon atoms, red: oxygen atoms, blue: nitrogen atoms. The location of these interactions in the ARM repeats highlight the greater interaction interface of the NiV W NLS for the importin $\alpha 3$ adaptor

conformation by superimposing the $\mathrm{HeV}$ W NLS from importin a3 onto the importin a1 structure. Although almost all other ARM repeat interactions remained the same, ARM repeats 7 and 8 of importin al clashed with the $\mathrm{HeV}$ W C terminus (Fig. 5b), indicating that the positioning of these ARM repeats in importin $\alpha 3$ allows for favourable interactions that are not possible with importin al.

As these ARM repeats appeared to be important for isoform specificity, we tested whether these regions were flexible and able to adapt to accommodate different NLSs. We superimposed importin $\alpha 1$ structures bound to a variety of NLSs including monopartite and bipartite, NLSs within domains including CAP80, and BiMax, and found that in all structures the importin al C-terminal ARM repeats 7 and 8 were in the same position (Fig. 5c). Similarly, superposition of a variety of importin a3 structures confirmed these regions are highly similar in all structures and allow for favourable binding (Fig. 5d). This supports the notion that the positioning of these ARM regions, highly similar across a wide range of structures, is conducive to high affinity binding of $\mathrm{W}$ in importin $\alpha 3$, but not importin $\alpha 1$.
Cargo-free importin $\alpha 1$ and $\alpha 3$ retain position of ARMs 7-8. To extend on the structural repertoire of importin a structures, we tested whether these ARM repeats are similar in the structures of importin $\alpha$ isoforms that do not contain bound cargo. Importin a1 and $\alpha 3$, crystallised in $\mathrm{P}_{1} 2_{1} 2_{1}$ and $\mathrm{P}_{1} 2_{1} 1$ space groups, respectively, both contained one chain in the ASU. This is the first report of these adaptors being crystallised without cargo bound in the NLS-binding pockets, although a dimer of importin al has been reported previously ${ }^{33}$. Comparison of the cargo-free and $\mathrm{W}$ NLS-bound forms of importin al showed that the structures were remarkably similar with an r.m.s.d of $0.180 \AA$ across 408 residues, and importantly, the positioning of ARM repeats 7 and 8 remain unchanged (Fig. 6a). Superposition of importin $\alpha 3$ in the cargo free and bound forms showed that the N-terminal ARM repeats 1-4 are repositioned by up to $5 \AA$ (Fig. 6b), consistent with previous findings that a more flexible hinge region is present in importin $\alpha 3^{15}$. However, the position of ARM repeats 7 and 8 was retained in both the cargo free and bound forms of importin a3. These results suggest that ARMs 7 and 8 do not undergo conformational changes to accommodate binding of the W NLS in either importin $\alpha 1$ or $\alpha 3$. Significantly, although the flexible hinge 
Table 1 Data collection and refinement statistics for importin $\alpha 1$ structures

\begin{tabular}{|c|c|c|c|}
\hline $\begin{array}{l}\text { Wavelength }(\AA) \\
\text { Space group } \\
\text { Cell dimensions }\end{array}$ & $\begin{array}{l}0.9537 \\
P 2_{1} 2_{1} 2_{1}\end{array}$ & $\begin{array}{l}0.9537 \\
P 2_{1} 2_{1} 2_{1}\end{array}$ & $\begin{array}{l}0.9537 \\
P 2_{1} 2_{1} 2_{1}\end{array}$ \\
\hline $\begin{array}{l}a, b, c(\AA) \\
\alpha, \beta, \gamma\left({ }^{\circ}\right) \\
\text { Resolution }(\AA) \\
R_{\text {pim }} \\
\text { Mean } I / \sigma(I) \\
C C_{1 / 2} \\
\text { Total reflections } \\
\text { Unique reflections } \\
\text { Completeness (\%) } \\
\text { Redundancy } \\
\text { Wilson } B \text {-factor } \\
\text { Refinement }\end{array}$ & $\begin{array}{l}78.5,90.0,100.7 \\
90,90,90 \\
24.54-2.50 \\
(2.60-2.50) \\
0.061(0.365) \\
10.2(2.9) \\
0.989(0.751) \\
154,003(17460) \\
24,805(2822) \\
98.6(100) \\
6.2(6.2) \\
26.4\end{array}$ & $\begin{array}{l}77.9,88.8,97.6 \\
90,90,90 \\
29.61-2.10 \\
(2.16-2.10) \\
0.033(0.253) \\
11.7(2.4) \\
0.998(0.814) \\
136,253(11369) \\
38,272(3193) \\
96(97.8) \\
3.6(3.6) \\
31.8\end{array}$ & $\begin{array}{l}79.0,89.3,100.4 \\
90,90,90 \\
19.76-2.20 \\
(2.28-2.20) \\
0.029(0.147) \\
18.5(5.4) \\
0.999(0.928) \\
208,967(18156) \\
36,721(3139) \\
99.8(100) \\
5.7(5.8) \\
22.6\end{array}$ \\
\hline $\begin{array}{l}\text { Refinement } \\
R_{\text {free }} \\
R_{\text {work }} \\
R_{\text {free }} \\
\text { Number of non-hydrogen atoms } \\
\text { Macromolecules } \\
\text { Protein residues } \\
\text { B factors } \\
\text { Protein } \\
\text { Water } \\
\text { R.M.S. deviations }\end{array}$ & $\begin{array}{l}24,772(2478) \\
1262(133) \\
0.1910(0.2227) \\
0.2129(0.2572) \\
3361 \\
3244 \\
426 \\
42.49 \\
42.66 \\
37.95\end{array}$ & $\begin{array}{l}38,216(3843) \\
1864(172) \\
0.1854(0.2690) \\
0.2032(0.3062) \\
3555 \\
3306 \\
434 \\
51.14 \\
51.31 \\
48.89\end{array}$ & $\begin{array}{l}36,662(3611) \\
1861(176) \\
0.1915(0.2257) \\
0.2121(0.2774) \\
3431 \\
3306 \\
434 \\
38.89 \\
38.98 \\
36.67\end{array}$ \\
\hline
\end{tabular}

region of importin $\alpha 3$ is unlikely to play a role in cargo containing an NLS in the C terminus of the protein (as the NLS ends before reaching the hinge region), the positioning of ARM repeats 1-3 could play a role in the binding of proteins harbouring an NLS at the $\mathrm{N}$ terminus, such as RCC1 (see Discussion).

Chimera of importin al ARMs 1-5: 3 ARMs 6-10 retains binding. To test our hypothesis that the positioning of ARM repeats 7 and 8 , located in the $C$ terminus of importin $\alpha 3$, mediate the isoform specificity for $\mathrm{W}$ protein, we examined whether chimeras comprised of importin $\alpha 1$ and importin $\alpha 3$ could mediate binding to $\mathrm{W}$ proteins (Fig. 7a). We found that a chimera comprised of the $\mathrm{N}$ terminus of importin $\alpha 1$ (IBB domain and ARMs 1-5) and the $C$ terminus of importin a3 (ARMs 6-10) (importin $\alpha 1^{\mathrm{ARM} 1-5}: \alpha 3^{\mathrm{ARM} 6-10}$ ) bound $\mathrm{W}$, whereas the reverse chimera comprised of importin $\alpha 3$ IBB ARMs 1-5 and importin a1 ARMs 6-10 (importin $\alpha 3^{\mathrm{ARM} 1-5}: \alpha 1^{\mathrm{ARM} 6-10}$ ) did not pulldown $\mathrm{W}$ (Fig. 7b). These results support the structural data that the C-terminal domain of importin $\alpha 3$ mediates isoform specificity for the $\mathrm{W}$ protein. Moreover, the importin a $1^{\mathrm{ARM1}-5}$ : a $3^{\mathrm{ARM} 6-10}$ bound with $8.3 \mathrm{nM}$ affinity to $\mathrm{HeV} \mathrm{W}$, and $4.7 \mathrm{nM}$ affinity to NiV W, comparable to the binding affinity of importin a3 (Supplementary Fig. 5). To further test the involvement of ARMs 7 and 8 in mediating specificity, we designed an importin a3 mutant based on the structural data to disrupt interactions in ARMs 7/8 (N348 A/N352A/E387A/N394A), and found a marked reduction in binding to both $\mathrm{HeV}$ and $\mathrm{NiV} \mathrm{W}$ proteins (Fig. $7 \mathrm{c}$ ). Confirming their functionality, both the importin a1 ARM1-5: $\alpha 3^{\text {ARM6-10 }}$ chimera and importin a3 ARMs 7/8 mutant retained the ability to bind to the SV40Tag classical NLS (Supplementary Fig. 6). The importin $a 3^{\mathrm{ARM} 1-5}: \alpha 1^{\mathrm{ARM} 6-10}$ formed inclusion bodies during overexpression and could not be purified. These results, together with the structural data, suggest that the positioning of the C-terminal ARM repeats 7 and 8 are important for mediating isoform specificity of henipavirus $\mathrm{W}$ proteins.

\section{Discussion}

In this study, we present high-resolution structures of importin a isoform adaptors bound to the NLS regions of $\mathrm{HeV} \mathrm{W}$ and NiV $\mathrm{W}$, providing insights into the molecular basis of importin a isoform specificity. We found that $\mathrm{HeV} \mathrm{W}$ and $\mathrm{NiV} \mathrm{W}$ proteins bind importin a3 preferentially, and that these NLS regions 
Table 2 Data collection and refinement statistics for importin $\alpha 3$ structures

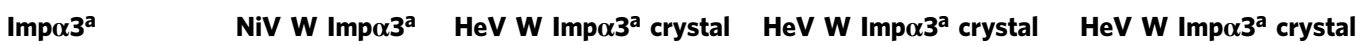

form 1 form 2 form 3

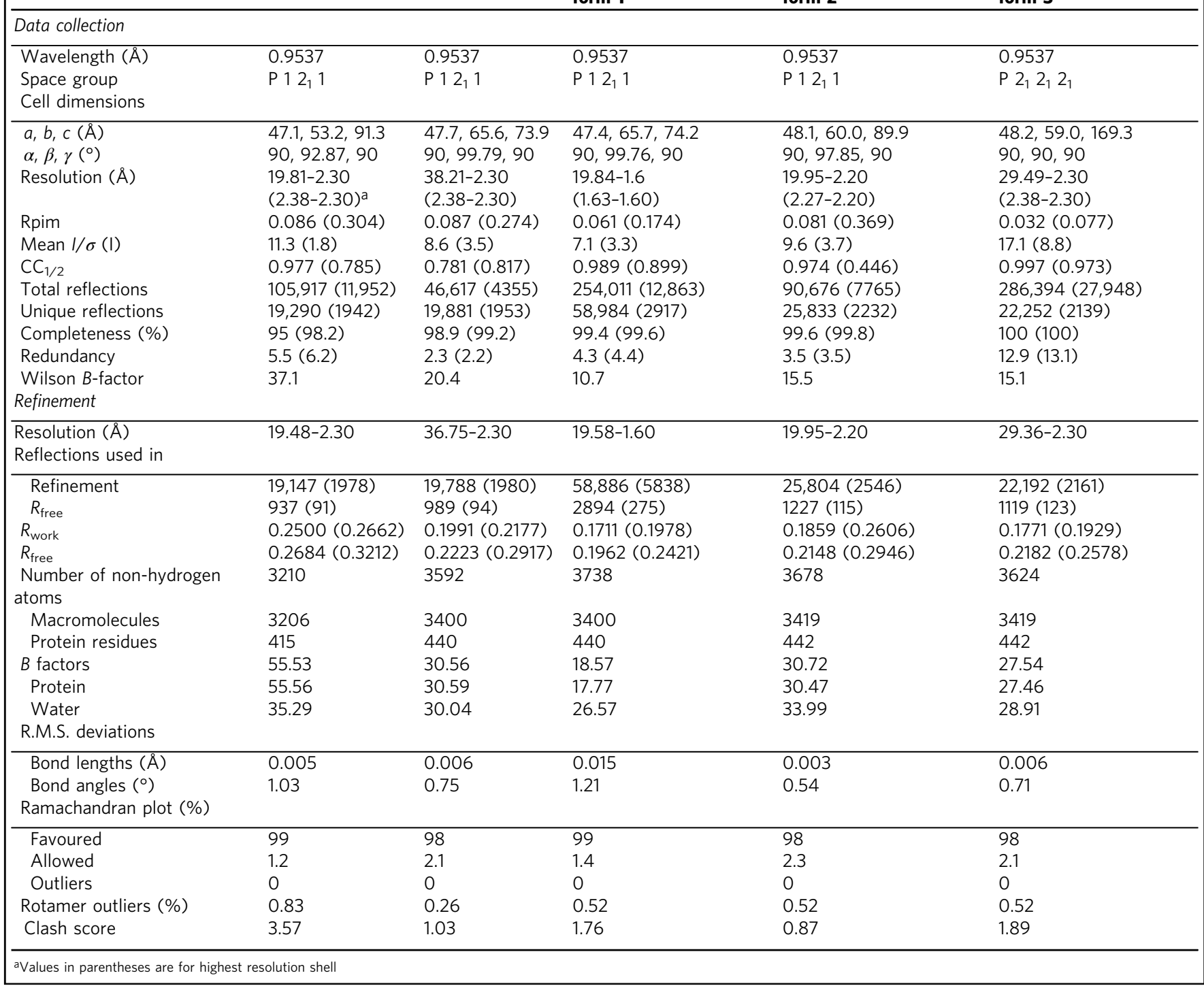

interact with higher affinity over other importin a subfamilies. Using structural approaches, we identified key features that account for adaptor specificity. We found that the isoform specificity was localised to the C-terminal ARM repeats 7 and 8, and that the positioning of these domains was an important determinant for mediating specificity.

Although numerous studies have reported specificity of nuclear adaptors for a wide range of cargo ${ }^{19,34-37}$ and associated function of these interactions in many diseases ${ }^{36}$, the mechanism(s) behind NLS adaptor specificity has remained elusive. Recently, one study described the specificity of the RCC1 factor for importin a3, highlighting that additional residues outside the NLS were important for maintaining specificity ${ }^{15}$. A comparison between the mechanism presented in the RCC1 study and our study, highlights a number of important differences. The study by Sankhala et al. ${ }^{15}$ indicated that the NLS of RCC1 binds in the major binding site of ARMS 2-4 of both importin $\alpha 1$ and $\alpha 3$, with additional interactions occurring at the $\mathrm{N}$ terminus of importin a3 ARM repeats $1-4$ and the $\beta$-propeller region of $\mathrm{RCC} 1$, mediated by flexibility and rotation of importin a3 in ARM repeats 1-2. This mechanism of isoform specificity is well suited to cargo containing NLSs at the $\mathrm{N}$ terminus, and our structural data of the unbound and NLS-bound forms of importin a3 supports this model. This mechanism is distinct, however, from that governing specificity for cargo such as the $\mathrm{W}$ proteins in this study, where the NLSs are located at the C terminus because the protein interface would not extend past the $\mathrm{N}$ terminus of ARM repeats 2-4. Thus, it may be possible that isoform specificity of cargo containing N-terminal NLSs may reside through differential interaction of the $\mathrm{N}$-terminal ARM repeats, whereas cargo bearing C-terminal NLSs may show specificity through differential interaction with the $\mathrm{C}$ terminus of importins, as demonstrated in this study. Although further work will be needed to establish how extensive these rules are, it is likely that different mechanisms may govern isoform specificity, dependent upon the position of the NLS within the cargo.

The findings of our study are distinct from mechanisms that have been previously hypothesised. The IBB domain has been 
a

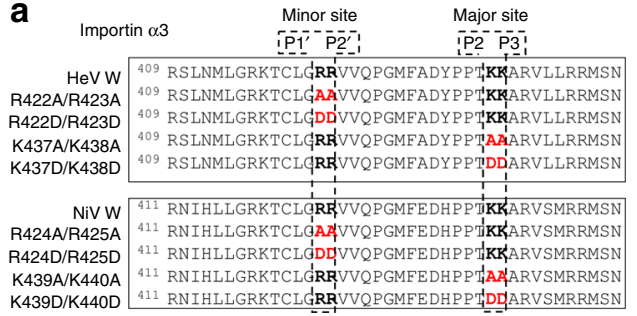

b

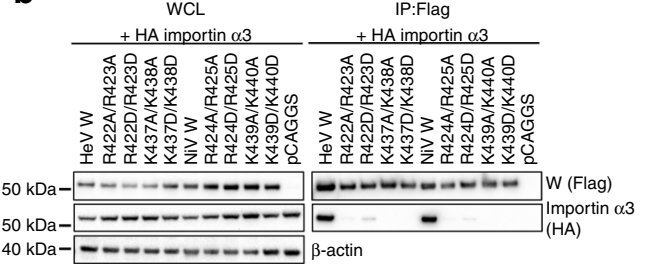

C

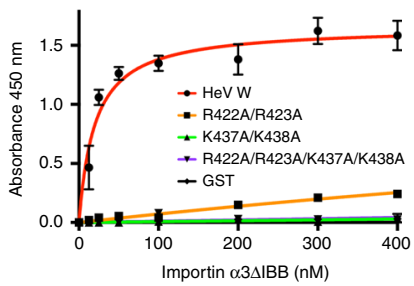

d
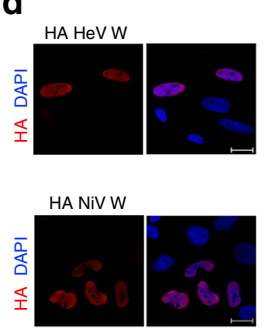

HA HeV W R422A/R423A

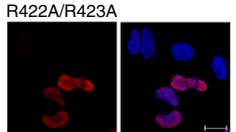

HA Niv W R424A/R425A

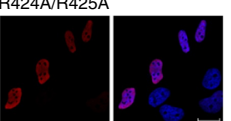

HA HeV W R422D/R423D

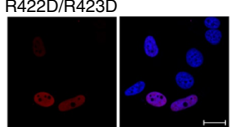

HA NiV W R424D/R425D

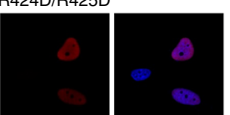

HA HeV W K437A/K438A

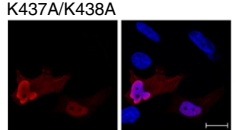

HA NiV W K439A/K440A

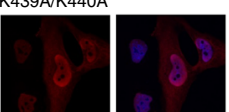

HA HeV W

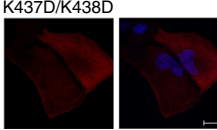

HA NiV W K439D/K440D

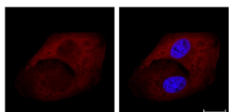

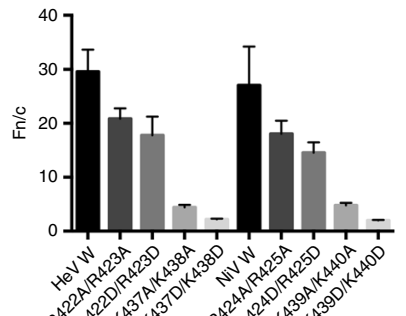

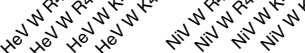

Fig. 4 Both importin $\alpha 3$ major and minor sites are important for the HeV NiV W protein interactions. a Schematic of the mutations made in the W protein to test the binding contributions at the major and minor binding sites for importin $\alpha 3$. b Co-immunoprecipitation assay performed with Flag antibody on lysates of HEK293T cells expressing HA-tagged importin $\alpha 3$ and Flag-tagged HeV W, NiV W, and mutant W constructs as indicated. Western blots were performed for HA and Flag. WCL, whole cell lysate; IP, immunoprecipitation. pCAGGS denotes empty vector control. c HeV W mutations were tested against importin $\alpha 3$ using the ELISA assay. GST-HeV W and mutants were coated on 96 -well plates, and binding of $6 \times$ His-tagged importin $\alpha 3$ assessed using an anti-6xHis HRP antibody. Error bars show the S.E.M for three replicates. d Hela cells were transfected with indicated HA-tagged HeV and NiV W plasmids. Twenty-four hours post transfection, cells were fixed and stained with anti-HA antibody and Alexa Fluor 594 to visualise protein localisation. Image is representative. Scale bar depicted is $20 \mu \mathrm{m}$. The ratio of nuclear to cytoplasmic fluorescence (Fn/c) was determined for 50 cells for each construct, error bars represent the SEM

shown to auto-inhibit differentially across isoforms ${ }^{19}$. However, our results identify clear differences in the structural positioning of the C-terminal ARM domains 7-8 of importin $\alpha 1$ and $\alpha 3$, accompanied with a significant increase in the binding interface at this region in importin $\alpha 3$. In addition, the chimeric protein importin $\alpha 1^{\mathrm{ARM} 1-5}: \alpha 3^{\mathrm{ARM}} 6-10$ binds to $\mathrm{W}$, whereas importin $\alpha 3^{\text {ARM1-5: }}: \alpha 1^{\text {ARM6-10 }}$ does not interact, confirming that the Cterminal domain of the importin $\alpha$ is the differentiating factor, rather than the $\mathrm{N}$ terminus. The importance of the $\mathrm{C}$-terminal ARM repeats has been demonstrated for importin a 5 binding of nonclassical NLS cargo, involving a distinct mechanism and ARM repeat $10^{38}$. It has also been hypothesised that that flexibility of importin a 3 may mediate increased specificity and/or affinity, and indeed, this was described as a contributing factor to the binding of RCC1. However, this is unlikely to have a role in the specificity of importin a3 for the $\mathrm{W}$ protein, because the difference in binding interactions occur outside of the hinge region. As well, if the hinge region was critical for mediating specificity, the $\alpha 3^{\text {ARM1-5 }}: \alpha 1^{\text {ARM6-10 }}$ chimera would have interacted with $W$ if the hinge region was the critical region for mediating specificity. In addition, we show through structural comparisons between apoand $\mathrm{W}$ bound-importin $\alpha 3$, that structural changes in the $\mathrm{N}$ terminus were not associated with direct binding interactions in this region. Importantly, these results do not discount the previous work of RCC1 binding, but rather, complement and extend it by highlighting that different mechanisms are likely to exist in mediating specificity.

Our study defines a basis to explain the importin a specificity of henipavirus $\mathrm{HeV} \mathrm{W}$ and $\mathrm{NiV} \mathrm{W}$ virulence factors for importins, demonstrating that differences in the ARM repeats in the $\mathrm{C}$ terminus of importin $a 3$ mediate specificity. Nuclear transport of cargo in an isoform and tissue-specific manner is critical for health and disease. Subtype switching of importin al to a5 in embryonic stem cells results in the initiation of neural differentiation ${ }^{39}$, and the maintenance and lineage determination of embryonic stem cells ${ }^{40}$. Differential expression of importin $a 3$ has been demonstrated to occur following rabies infection, with overexpression observed only in paralytic rabies, suggesting a possible prognostic marker ${ }^{41}$. The inhibition of importin $\alpha 3$ has also been shown to attenuate prostate cancer mestastasis ${ }^{42}$. The expanded rules for isoform specificity outlined here will provide important insights into our understanding of nuclear transport adaptor cargo specificity and their function in cellular processes.

\section{Methods}

Plasmids for recombinant protein expression. The $\mathrm{C}$-terminal domain of $\mathrm{HeV}$ (residues 409-448; UniProtKB P0C1C6) and NiV (residues 411-450; UniProtKB P0C1C7) with an N-terminal TEV cleavage site (ENLYFQS) were codon optimised for expression in Escherichia coli and synthesised (Genscript, Piscataway, NJ). These constructs were cloned into pGEX4T-1 vector at Bam HI and EcoRI sites. Importin $\alpha 3$ and $\alpha 7$ lacking the auto-inhibitory IBB domain (residues 64-521 and 73-536) were codon optimised for E. coli expression, synthesised and cloned into pET15b vector at NdeI and EcoRI sites. The importin a chimeras lacking the autoinhibitory IBB domain (for recombinant expression) were comprised of alaa71-279: a3aa271-521 and a3aa64-270:a1aa280-529, with numbering according to UniProtKB P52292 and UniProtKB O00629 for importin al and importin $\alpha 3$, respectively. Importin $\alpha 1 \Delta \mathrm{IBB}$, encoding residues $71-529$, was cloned in the pET30 vector as described previously ${ }^{43,44}$.

Recombinant expression and purification. Plasmids were transformed into BL21 (DE3) pLysS cells and expressed using the Studier auto-induction method ${ }^{45}$. In brief, starter cultures were inoculated into $2 \mathrm{~L}$ baffled flasks containing $500 \mathrm{~mL}$ of expression media consisting of $1 \%(\mathrm{w} / \mathrm{v})$ tryptone, $0.5 \%(\mathrm{w} / \mathrm{v})$ yeast extract, $0.5 \%$ glycerol, $0.05 \%$ glucose, $0.2 \%$ (w/v) a-lactose, $0.025 \mathrm{M} \mathrm{NH}_{4} \mathrm{SO}_{4}, 0.05 \mathrm{M} \mathrm{KH}_{2} \mathrm{PO}_{4}$, $0.05 \mathrm{M} \mathrm{Na}_{2} \mathrm{HPO}_{4}, 1 \mathrm{mM}$ magnesium chloride and either $100 \mu \mathrm{g} / \mathrm{mL}$ ampicillin, or $50 \mu \mathrm{g} / \mathrm{mL}$ kanamycin. Cells were harvested via centrifugation at $6500 \times \mathrm{g}$ and $18^{\circ} \mathrm{C}$ for $30 \mathrm{~min}$ and resuspended in phosphate buffer (PB) $(20 \mathrm{mM}$ imidazole, $300 \mathrm{mM}$ $\mathrm{NaCl}, 50 \mathrm{mM}$ phosphate $\mathrm{pH} 8.0$ ) or Tris-buffered saline (TBS) (Tris $\mathrm{pH} 8.0,125$ $\mathrm{mM} \mathrm{NaCl}$ ) buffer with complete ethylenediaminetetraacetic acid (EDTA)-free 
a

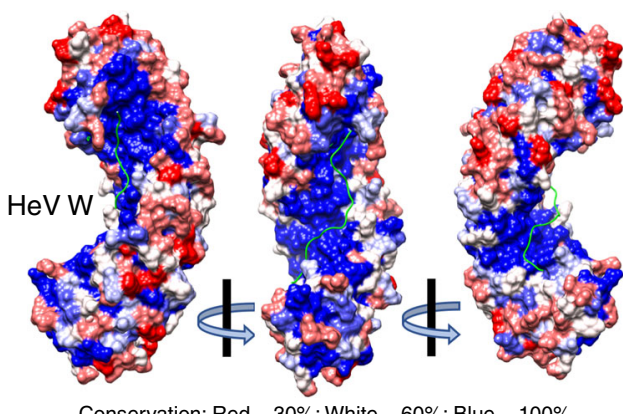

Conservation: Red - 30\%; White $-60 \%$; Blue $-100 \%$ b

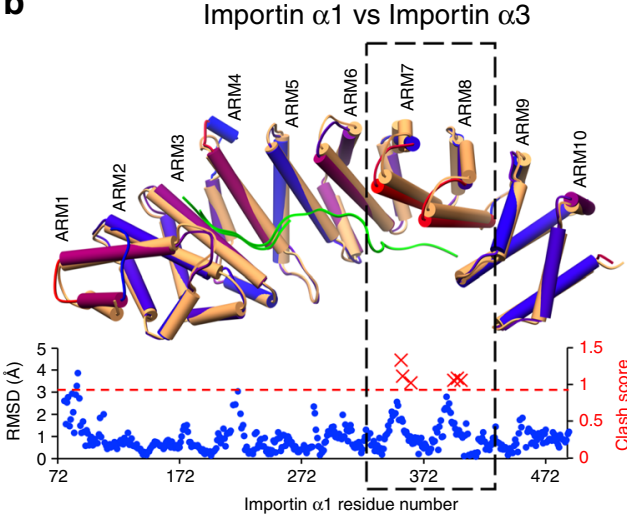

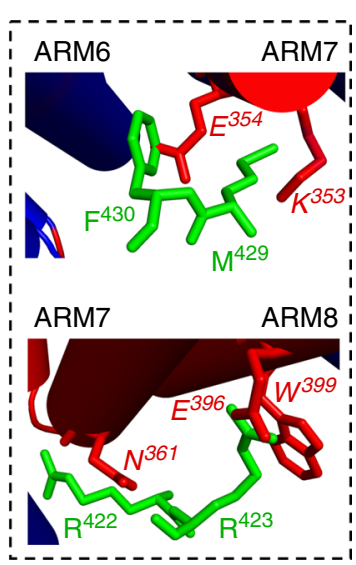

C

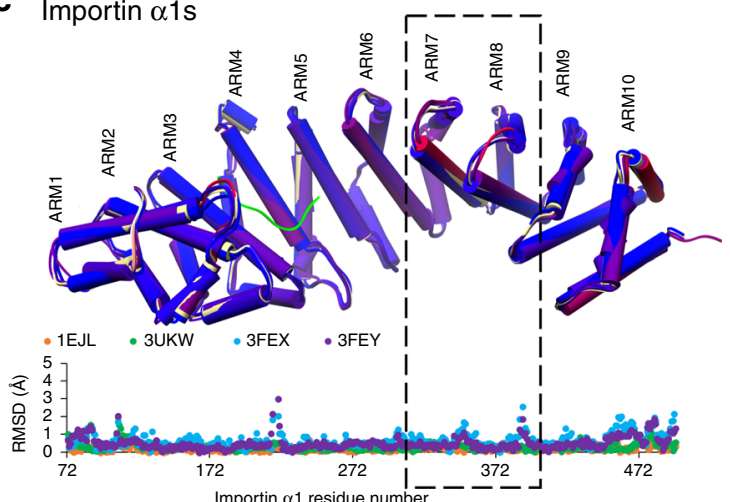

d Importin $\alpha 3 \mathrm{~s}$

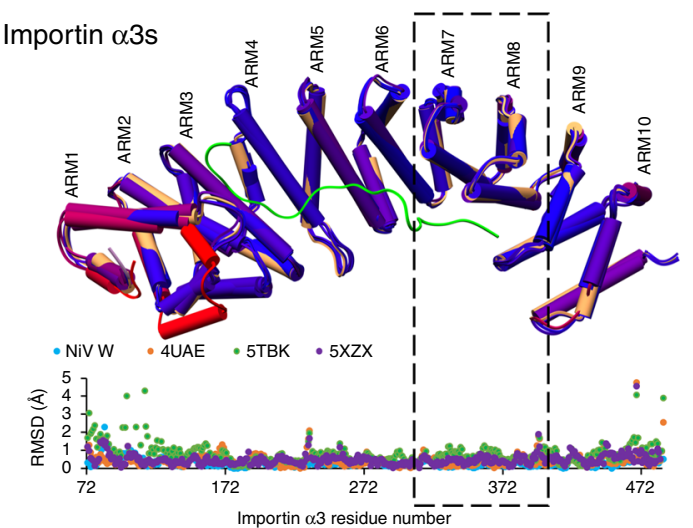

Fig. 5 Structural basis for specificity of Henipavirus W binding to the importin $\alpha 3$. a Importin $\alpha 3$ :HeV W structure coloured by conservation of amino acids across all importin $\alpha$ isoforms highlights a 100\% conservation in the binding interface. The HeV W NLS backbone (coloured green) is shown in complex with importin $\alpha 3$, with sequence colour rendering red at 30\%, white 60\%, and blue 100\% sequence identity. Figure created in UCSF Chimera using importin $\alpha$ alignments from Clustal Omega. b To identify structural differences, the structures of importin $\alpha 1: H e V W$ and importin $\alpha 3: H e V$ W were superimposed in UCSF Chimera using MatchEnsemble, and r.m.s.d. plots generated using MatchAlign, and MatchAssess functions. $\alpha$-helices shown as cylinders; importin $\alpha 3$ coloured orange throughout, and colour conservation rendering for importin $\alpha 1$ set for blue, $<2.5 \AA$ variance, and red for variances $>$ $2.5 \AA$. Molprobity was used to analyse clash data of importin $\alpha 3$ : HeV W NLS superimposed to importin $\alpha 1$, all clashes $>0.8$ shown as red crosses. Differences in clash score between importin $\alpha 1$ and $\alpha 3$ are localised to ARMs 7 and 8 . Detailed view of clashes are presented in the right box, highlighting residues clashing with the W NLS owing to the difference in positioning of ARMs 7 and 8 in importin $\alpha 1$. All clashing residues are positioned on the $\alpha$ helices of the ARMs. c Structural comparisons of importin $\alpha 1$ bound to a range of cargo was examined by superimposing the $\alpha 1$ :HeV W NLS structure determined in this study (reference molecule, coloured yellow), with importin $\alpha 1$ bound to a monopartite SV40T NLS 12 (1EJL), bipartite Bimax NLS 59,60 (3UKW), and two domain bound structures of CAP8061 (3FEX, 3FEY) coloured according to r.m.s.d as described in b. Positioning of the $\alpha$-helices in ARMs 7 and 8 are relatively static across all structures. $\mathbf{d}$ Structural comparisons of importin $\alpha 3$ bound to a range of cargo was examined by superimposing the $\alpha 3: \mathrm{HeV}$ W NLS structure determined in this study (reference molecule coloured orange) with the monopartite RanBP362 (5ZXZ), the NiV W (this study), and domains of PB2 ${ }^{19}$ (4UAE) and RCC1 ${ }^{15}$ (5TBK) coloured according to r.m.s.d as described in $\mathbf{b}$. Positioning of $\alpha$-helices in ARMs 7 and 8 are also relatively static across all structures

protease inhibitor. Cells were lysed using two freeze-thaw cycles and addition of $20 \mathrm{mg}$ lysozyme and $0.5 \mathrm{mg}$ DNase.

Affinity purifications of $6 \mathrm{xHis}$-tagged importin a were performed by injecting clarified cell lysate onto a GE HisTrap $5 \mathrm{~mL}$ column using PB, washing the column with 15 column volumes and then eluting over 5 column volumes using a gradient elution with high imidazole PB $(500 \mathrm{mM}$ imidazole, $300 \mathrm{mM} \mathrm{NaCl}, 50 \mathrm{mM}$ phosphate $\mathrm{pH}$ 8.0). Affinity purifications of GST-tagged proteins were performed on a GST Trap $5 \mathrm{~mL}$ column using TBS, and elution buffer containing $10 \mathrm{mM}$ glutathione. All size exclusion purifications were performed on a Superdex $200 \mathrm{pg}$ 26/600 column using TBS pH 8.0, and eluted proteins were pooled and concentrated using $10 \mathrm{kDa}$ MW centrifuge filters. Complex formation was performed as described previously ${ }^{46}$.

ELISA. The method was based on previously published microtiter plate assays ${ }^{47}$. In brief, 96-well clear plates were coated with GST-NLS fusion proteins using bicarbonate/carbonate buffer $\mathrm{pH} 9.6$ for $2 \mathrm{~h}$ at room temperature. The plates were washed using TBS containing $0.05 \% \mathrm{v} / \mathrm{v}$ Tween 20 (TBST). Blocking was achieved using $5 \%(\mathrm{w} / \mathrm{v})$ skim milk in TBST for $2 \mathrm{~h}$ at room temperature. Wells were washed three times in TBST buffer and incubated with decreasing concentrations of 6xHis- tagged importin $a \Delta \mathrm{IBB}(400,300,200,100,50,25,12.5$ and $0 \mathrm{nM})$ diluted in TBS for $2 \mathrm{~h}$. The plate was washed three times, blocked for $2 \mathrm{~h}$, washed a further three times and then incubated for $2 \mathrm{~h}$ with $100 \mu \mathrm{L}$ a 1/5000 dilution of anti-6xHis $4 \mathrm{HRP}$ conjugated rabbit polyclonal antibody (Abcam ab1187). The plate was washed a further three times before addition of $100 \mu \mathrm{L}$ of TMB substrate (Sigma T4444). The colorimetric reaction proceeded for $20 \mathrm{~min}$ before being stopped with $100 \mu \mathrm{L}$ of 2 $\mathrm{M} \mathrm{H}_{2} \mathrm{SO}_{4}$, and the absorbance measured at $450 \mathrm{~nm}$ using an Epoch microplate spectrophotometer (Biotek). One-site specific binding analysis using least squares fit was performed using GraphPad Prism version 7.00 for Mac, GraphPad Software, La Jolla California USA, www.graphpad.com.

Microscale thermophoresis. Affinity measurements using MST were carried out employing a Monolith NT.115 instrument (NanoTemper Technologies) ${ }^{48}$. Purified importin $\alpha 1, \alpha 3$ and $\alpha 7$ in $20 \mathrm{mM}$ 4-(2-hydroxyethyl)-1-piperazineethanesulfonic acid (HEPES), $150 \mathrm{mM} \mathrm{NaCl}$, pH 8.0 were labelled using the NHS RED NanoTemper labelling kit according to the manufacturer's instructions. For the assay, 5 $\mu \mathrm{L}$ of labelled protein was mixed with $10 \mu \mathrm{L}$ of the unlabelled $\mathrm{NiV}$ W at various concentrations and $5 \mu \mathrm{L}$ of $0.05 \%(\mathrm{w} / \mathrm{v})$ Tween 20 . All experiments were incubated for $10 \mathrm{~min}$ before applying samples to Monolith NT Standard Treated Capillaries 
a Importin $\alpha 1$ cargo-free vs HeV W bound structures

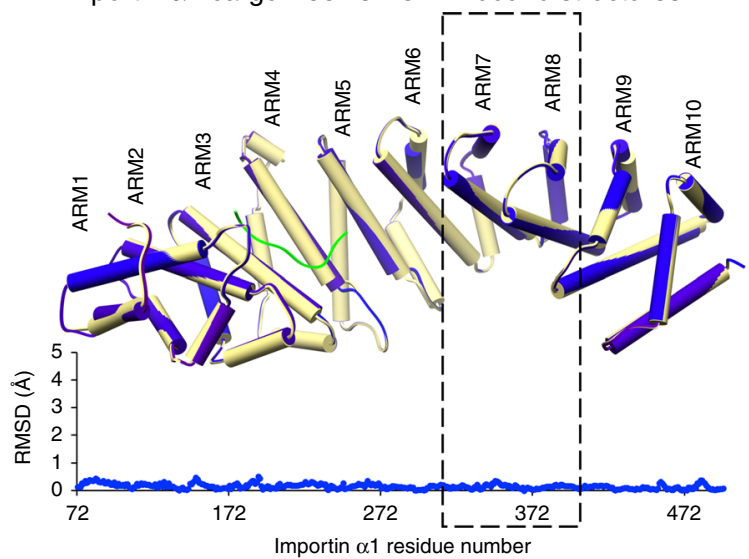

b Importin $\alpha 3$ cargo-free vs HeV W bound structures

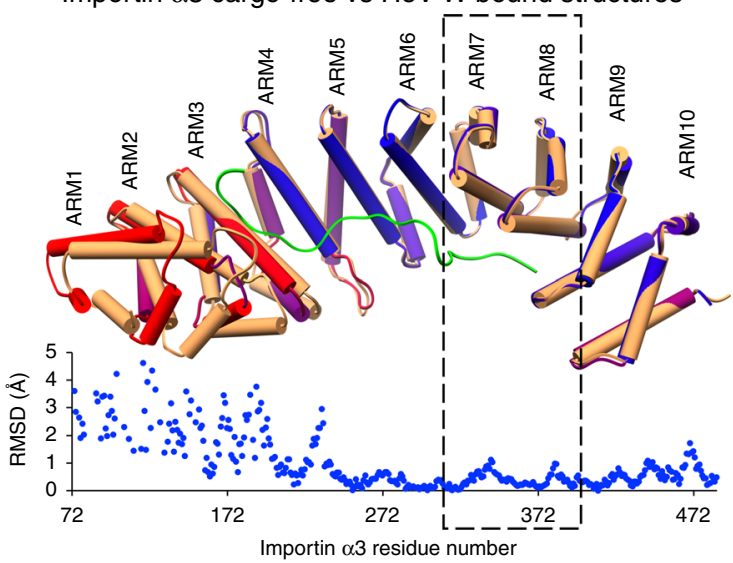

Fig. 6 Structures of cargo-free importin $\alpha 1$ and $\alpha 3$ confirm ARMs 7 and 8 positioning. a Importin $\alpha 1$ cargo-free structure and structural superposition with importin $\alpha 1: \mathrm{HeV}$ W complex (reference molecule, coloured yellow) and associated r.m.s.d plot. The positioning of the $\alpha$-helices in ARM repeats 7 and 8 are static across all structures. The importin $\alpha 1$ is coloured by r.m.s.d rendering where blue $<2.5 \AA$ variance, and red for variances above $2.5 \AA$. $\mathbf{b}$ Importin $\alpha 3$ cargo-free structure, together with the associated structural superposition with importin $\alpha 3$ HeV W complex, and r.m.s.d plot. Importin $\alpha$ structures were aligned in UCSF Chimera using MatchEnsemble, and r.m.s.d. plots were generated using MatchAlign, and MatchAssess functions. Colouring as per $\mathbf{a}$, but with importin $\alpha 3: \mathrm{HeV} \mathrm{W}$ in orange

a

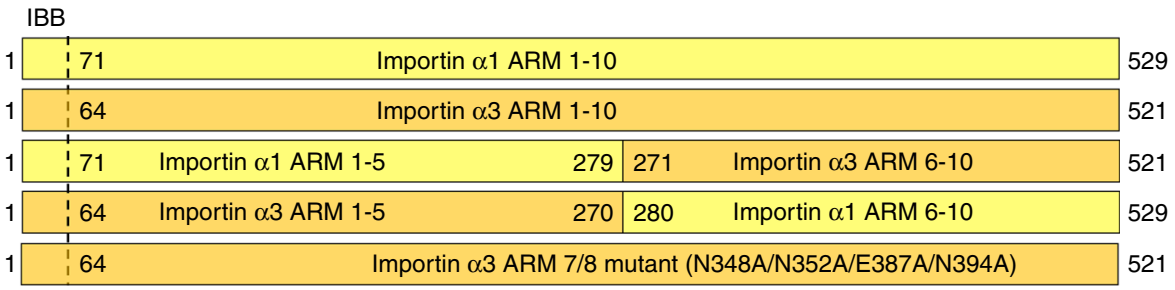

b

Flag importin $\alpha 1+\ldots$ Input

Flag importin $\alpha 3-+---+---+--++--$

Flag importin $\alpha 1 \mathrm{ARM}^{1-5}$ : $\alpha 3 \mathrm{ARM}^{6-10}-\ldots+-\ldots+-+-\ldots+-\ldots$

Flag importin $\alpha 3 \mathrm{ARM}^{1-5}: \alpha \mathrm{ARMM}^{6-10}-\cdots+\cdots+-+-\cdots+-\cdots+$

$\mathrm{HAHeVW}+++++-\ldots-\ldots+++++-\ldots$

HA NiV W - - - + + + + + - - - + + + +

pCAGGS $\ldots \ldots+\ldots+\ldots+\ldots+\ldots$

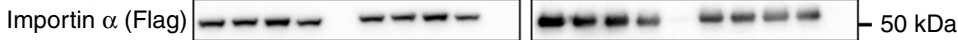

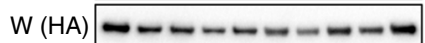

$\beta$-actin

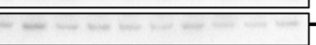

- - $-50 \mathrm{kDa}$

C

Input IP:HA

$\mathrm{HA} \mathrm{HeVW}++-\ldots++-\ldots$

HA NiV W - + + - - - + + -

Flag importin $\alpha 3+-+-+-++++-$

Flag importin $\alpha 3$ ARM7/8 mutant -++++-++-+

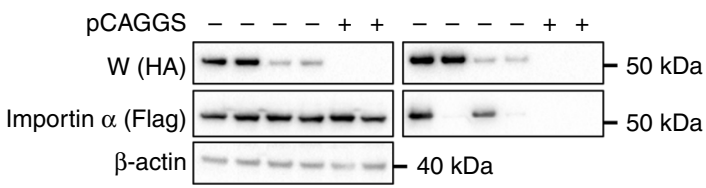

Fig. 7 Confirming the structural hypothesis through importin $\alpha$ chimeras. a Schematic representation of importin $\alpha 1, \alpha 3$, and chimeric importin $\alpha 1^{A R M 1-5}$ :

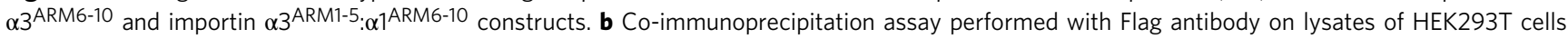
expressing Flag-tagged importin $\alpha 1, \alpha 3$, importin $\alpha 1^{A R M 1-5}: \alpha 3^{A R M 6-10}$ and importin $\alpha 3^{A R M 1-5}: \alpha 1^{A R M 6-10}$, and HA-tagged HeV W and NiV W, as indicated. Western blots were performed for HA and Flag. WCL, whole cell lysate; IP, immunoprecipitation. pCAGGS denotes empty vector control. c Co-

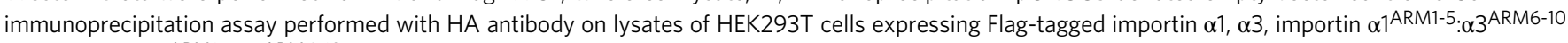
and importin $\alpha 3^{A R M 1-5:}: \alpha 7^{A R M 6-10}$, and HA-tagged HeV W and NiV W, as indicated. Western blots were performed for HA and Flag. WCL, whole-cell lysate; IP, immunoprecipitation. pCAGGS denotes empty vector control 
(NanoTemper Technologies). Thermophoresis was measured at $25^{\circ} \mathrm{C}$ with laser off/on/off times of $5 \mathrm{~s} / 30 \mathrm{~s} / 5 \mathrm{~s}$. Experiments were conducted at $20 \%$ light-emitting diode power and $20-40 \%$ MST infra-red laser power. Data from three independently performed experiments were fitted to the single binding model via the NT. Analysis software version 1.5.41 (NanoTemper Technologies) using the signal from Thermophoresis + T-Jump.

Crystallisation. All crystals were obtained using the hanging drop vapour diffusion method over a $300 \mu \mathrm{L}$ reservoir solution. Importin $\alpha 1 \Delta \mathrm{IBB}$ was crystallised with 1 $\mathrm{M} \mathrm{NH}_{4} \mathrm{SO}_{4}, 0.01 \mathrm{M} \mathrm{DTT}, 0.1 \mathrm{M}$ sodium HEPES pH 7.0. The importin $\alpha 1 \Delta \mathrm{IBB}: \mathrm{NiV}$ $\mathrm{W}$ and importin $\alpha 1 \Delta \mathrm{IBB}: \mathrm{HeV} \mathrm{W}$ complexes were crystallised in $0.01 \mathrm{M}$ DTT, 0.7 $\mathrm{M}$ sodium citrate and $0.1 \mathrm{M}$ sodium HEPES $\mathrm{pH} 7.0$, with rod-shaped crystals forming within 2-3 days. Importin $\alpha 3 \Delta \mathrm{IBB}$ was crystallised using $0.2 \mathrm{M}$ sodium nitrate, 0.1 M Bis-Tris propane $\mathrm{pH} 6.5$ and 25\% (w/v) PEG 3350. Plate-like crystals formed within 2-3 weeks. The importin a $3 \Delta \mathrm{IBB}: \mathrm{NiV} \mathrm{W}$ complex crystallised in $0.2 \mathrm{M}$ lithium nitrate, $20 \%$ (w/v) PEG 3350 conditions with a rod morphology that diffracted to $2.3 \AA$. The importin $\alpha 3 \Delta \mathrm{IBB}: \mathrm{HeV} \mathrm{W}$ complex crystallised in three forms. Crystal form 1 was obtained using $0.1 \mathrm{M}$ sodium citrate $\mathrm{pH} 5.0$ and $20 \%$ (w/ v) PEG 2000, crystal form 2 was obtained using $0.1 \mathrm{M}$ sodium HEPES pH 7.5, 25\% (w/v) PEG 200 MME and crystal form 3 obtained using $0.2 \mathrm{M}$ sodium chloride, 0.1 M MES pH 6.5, 10\% (w/v) PEG 4000 conditions. Diffraction of the importin a $3 \triangle \mathrm{IBB}: \mathrm{HeV}$ W complex crystal forms ranged from 1.6-2.3 $\mathrm{A}$.

Data collection and processing. X-ray diffraction data were collected at the Australian Synchrotron on the MX1 $1^{49}$ and $\mathrm{MX}^{50}$ macromolecular beam lines using an ASDC Quantum 210r, ASDC Quantum 315r detector and Eiger $16 \mathrm{M}$ detector, respectively. Data reduction and integration was performed using iMosflm ${ }^{51}$ for data collected using ADSC 210r and ADSC 315r detectors, whereas reduction and integration of data collected on Eiger $16 \mathrm{M}$ was performed using $\mathrm{XDS}^{52}$. Merging, space group assignment, scaling and selection of 5\% reflections for $\mathrm{R}_{\text {free }}$ calculations was done using Aimless $s^{53,54}$ and the CCP4 suite ${ }^{55}$. Phasing was performed using molecular replacement in Phaser $\mathrm{MR}^{56}$, with PDBID 5FC8 used as a search model for importin al cargo-free, importin $\alpha 1: H e V$ W complex and importin $\alpha 1: \mathrm{NiV} \mathrm{W}$. The importin $\alpha 3: \mathrm{HeV} \mathrm{W}$ complex was phased using $4 \mathrm{UAE}$ as a search model, from which the solution was then used as a search model for the importin $\alpha 3: \mathrm{NiV} \mathrm{W}$ complex. The cargo-free importin $\alpha 3$ structure was phased by placing the $\mathrm{N}$ terminus and $\mathrm{C}$ terminus domains separately. Models were refined using iterative cycles of manual real space $\operatorname{coot}^{57}$ and maximum likelihood phenix refine ${ }^{58}$

Cell culture and plasmids. HEK293T (ATCC-CRL-3216) and Hela cells (ATCC -CCL-2) were maintained in Dulbecco's Modified Eagle Medium, supplemented with $10 \%$ fetal bovine serum and cultured at $37^{\circ} \mathrm{C}$ and $5 \% \mathrm{CO}_{2}$.

The sequence for HeV W (NCBI: JN255804.1) was synthesised (Genscript, Piscataway, NJ) and cloned with N-terminal Flag- and HA-tags into the mammalian expression plasmid pCAGGS. pCAGGS HA NiV W was previously described $^{20}$. NiV W was subcloned with a Flag-tag into pCAGGS. Overlapping PCR was used to clone $\mathrm{HeV}$ W R422A/R423A, HeV W R422D/R423D, HeV W K437A/K438A, HeV W K437D/K438D, NiV W R424A/R425A, NiV W R424D/ R425D, NiV W K439A/K440A, NiV W K439D/K440D and importin a3 ARMs 7/8 mutant (N348 A/N352A/E387A/N394A), which were then cloned with an HA- or Flag-tag into pCAGGS. pCAGGS Flag importin $\alpha 1, \alpha 3, \alpha 4, \alpha 5, \alpha 6$ and $\alpha 7$ were previously described 20,36 . Importin $a 3$ was subcloned with an HA-tag into pCAGGS. Overlapping PCR was used to generate the chimeric importin $\alpha 1^{A R M 1-5 .}$

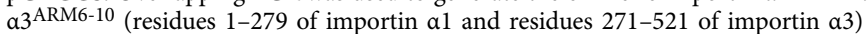
and importin $\alpha 3^{\mathrm{ARM1}-5}: \alpha 1^{\mathrm{ARM} 6-10}$ (residues 1-270 of importin $\alpha 3$ and residues 280-529 of importin $\alpha 1$ ), which were cloned with Flag tags into pCAGGS. For additional information regarding primers used in this study, please see Supplementary Table 6 .

Co-immunoprecipitation assays. HEK293T cells $\left(1 \times 10^{6}\right)$ were transfected with the indicated plasmids using Lipofectamine 2000 (Thermo Fisher Scientific, MA) and at $24 \mathrm{~h}$ post transfection, cells were lysed in NP-40 lysis buffer $(50 \mathrm{mM}$ Tris $\mathrm{pH} 7.5$, $280 \mathrm{mM} \mathrm{NaCl}, 0.5 \%$ Nonidet P-40, $0.2 \mathrm{mM}$ EDTA, $2 \mathrm{mM}$ ethylene glycol-bis( $\beta$ aminoethyl ether)-N,N,N',N'-tetraacetic acid, $10 \%$ glycerol, protease inhibitor (complete; Roche, Indianapolis, IN)). Anti-FLAG M2 magnetic beads or EZview Red antiHA Agarose affinity gel (Sigma-Aldrich, St. Louis, MO) were incubated as indicated with lysates for $1 \mathrm{~h}$ at $4^{\circ} \mathrm{C}$, washed five times in NP-40 lysis buffer, and eluted using 3X FLAG or HA peptide (Sigma-Aldrich, St. Louis, MO) at $4^{\circ} \mathrm{C}$ for $30 \mathrm{~min}$. Whole cell lysates and co-precipitation samples were analysed by western blot.

Immunofluorescence. Hela cells $\left(3 \times 10^{4}\right)$ grown on glass coverslips were transfected with indicated $\mathrm{HeV}$ and $\mathrm{NiV} \mathrm{W}$ plasmids (300 ng) using Lipofectamine 2000 (Thermo Fisher Scientific, MA). At $24 \mathrm{~h}$ post transfection, cells were fixed using $4 \%$ paraformaldehyde and permeabilised using $0.1 \%$ Triton X-100. Cells were stained using mouse anti-HA (H3663, Sigma-Aldrich, MO) (dilution 1:500) and secondary antibody conjugated to Alexa Fluor 594 (A-11032, Thermo Fisher Scientific, MA) (dilution 1:2000). Images were taken using a Zeiss LSM 800 confocal microscope at $\times 64$. To determine the ratio of nuclear to cytoplasmic fluorescence signal $(\mathrm{Fn} / \mathrm{c})$,
Hela cells $\left(1 \times 10^{4}\right)$ were plated in a 96-well plate (black, clear bottom, Corning) and transfected with the indicated $\mathrm{HeV}$ and $\mathrm{NiV}$ W plasmids (300 ng) using Lipofectamine 2000. At $24 \mathrm{~h}$ post transfection, cells were fixed and permeabilised as above and stained with anti-HA (H6908, Sigma-Aldrich, MO) (dilution 1:500) and Alexa Fluor 488 (A32731, Thermo Fisher Scientific, MA) (dilution 1:2000). Images were taken at $\times 10$ using a BioTek Cytation 5 Cell Imaging Multi-Mode reader and were analysed using Gen5 Image Prime software to determine Fn/c, using the calculation $\mathrm{Fn} / \mathrm{c}=$ (Fn-background) $/(\mathrm{Fc}$-background), where Fn is nuclear fluorescence and $\mathrm{Fc}$ is cytoplasmic fluorescence. $\mathrm{Fn} / \mathrm{c}$ was determined for 50 cells in each condition; error bars indicate the standard error of the mean (SEM).

Antibodies. Polyclonal rabbit anti-Flag (F7425), polyclonal rabbit anti-HA (H6908), and monoclonal mouse anti-HA (H3663) were purchased from SigmaAldrich (St. Louis, MO). Monoclonal rabbit $\beta$-actin antibody was purchased from Cell Signalling (4967 S) (Danvers, MA).

Western blots. Lysates were run on 10\% Bis-Tris Plus polyacrylamide gels (Thermo Fisher Scientific, MA) and transferred to polyvinylidene difluoride membrane (BioRad, Hercules, CA). Membranes were probed with the indicated antibodies and were developed using Western Lightning Plus ECL (Perkin Elmer, Waltham, MA) and imaged using a ChemiDoc MP Imaging System (Bio-Rad, Hercules, CA).

GST pull-down assay. Each binding experiment was comprised of $100 \mu \mathrm{L}$ of 30 $\mu \mathrm{M}$ GST or GST-SV40Tag, combined with $100 \mu \mathrm{L}$ of $30 \mu \mathrm{M}$ of each importin $\alpha$ variant, and incubated at room temperature for $2 \mathrm{~h}$ with $50 \mu \mathrm{L}$ of glutathione agarose beads (Sigma G4510). The beads were centrifuged and washed three times with $1 \mathrm{~mL}$ Tris wash buffer $(125 \mathrm{mM} \mathrm{NaCl}$, Tris $\mathrm{pH}$ 8.0). Samples were centrifuged, the supernatant discarded, and $50 \mu \mathrm{L}$ sodium dodecyl sulfate polyacrylamide gel electrophoresis (SDS-PAGE) loading buffer containing $100 \mathrm{mM}$ DTT was added to each tube. Samples were heated for $10 \mathrm{~min}$ at $95^{\circ} \mathrm{C}$, vortexed for $5 \mathrm{~min}$, centrifuged for $10 \mathrm{~min}$ at $17000 \times g$ and analysed by SDS-PAGE ( $165 \mathrm{~V}$ for $30 \mathrm{~min}$ on a $4-12 \%$ Bis-Tris plus gel (Novagen)).

\section{Data availability}

Atomic coordinates and related structure factors have been deposited to the Protein Data Bank with accession codes 6BW1, 6BW0, 6BW9, 6BWA, 6BWB, 6BVV, 6BVT and 6BVZ for the importin $\alpha 1: \mathrm{HeV} \mathrm{W}\left(\mathrm{P} 2_{1} 2_{1} 2_{1}\right.$ space group), importin $\alpha 1: \mathrm{NiV} \mathrm{W}\left(\mathrm{P} 2_{1} 2_{1} 2_{1}\right.$ space group), importin $\alpha 3: \mathrm{HeV} \mathrm{W}$ crystal form 1 (P12 1 space group), importin $\alpha 3: \mathrm{HeV} \mathrm{W}$ crystal form 2 (P12 1 space group), importin $\alpha 3: \mathrm{HeV} \mathrm{W}$ crystal form 3 ( $\mathrm{P} 2_{1} 2_{1} 2_{1}$ space group), importin $\alpha 3: \mathrm{NiV} \mathrm{W}$ ( $\mathrm{P} 12_{1} 1$ space group), importin $\alpha 1$ ( $\mathrm{P} 2{ }_{1} 2_{1} 2_{1}$ space group), importin $\alpha 3$ ( $\mathrm{P} 12_{1} 1$ space group), respectively. All other data that support the findings of this study are available from the corresponding authors on reasonable request.

Received: 21 December 2017 Accepted: 29 June 2018 Published online: 12 September 2018

\section{References}

1. Macara, I. G. Transport into and out of the nucleus. Microbiol. Mol. Biol. Rev. 65, 570-594 (2001)

2. Bednenko, J., Cingolani, G. \& Gerace, L. Nucleocytoplasmic transport: navigating the channel. Traffic 4, 127-135 (2003).

3. Stewart, M. Molecular mechanism of the nuclear protein import cycle. Nat. Rev. Mol. Cell Biol. 8, 195-208 (2007).

4. Goldfarb, D. S., Corbett, A. H., Mason, D. A., Harreman, M. T. \& Adam, S. A. Importin alpha: a multipurpose nuclear-transport receptor. Trends. Cell Biol. 14, 505-514 (2004).

5. Cingolani, G., Petosa, C., Weis, K. \& Müller, C. W. Structure of importin- $\beta$ bound to the IBB domain of importin- $\alpha$. Nature 399, 221-229 (1999).

6. Milles, S. et al. Plasticity of an ultrafast interaction between nucleoporins and nuclear transport receptors. Cell 163, 734-745 (2015).

7. Lee, S. J., Matsuura, Y., Liu, S. M. \& Stewart, M. Structural basis for nuclear import complex dissociation by RanGTP. Nature 435, 693-696 (2005).

8. Moroianu, J., Blobel, G. \& Radu, A. Nuclear protein import: Ran-GTP dissociates the karyopherin alphabeta heterodimer by displacing alpha from an overlapping binding site on beta. Proc. Natl. Acad. Sci. 93, 7059-7062 (1996)

9. Kutay, U., Bischoff, F. R., Kostka, S., Kraft, R. \& Gorlich, D. Export of importin alpha from the nucleus is mediated by a specific nuclear transport factor. Cell 90, 1061-1071 (1997).

10. Bischoff, F. R. \& Görlich, D. RanBP1 is crucial for the release of RanGTP from importin $\beta$-related nuclear transport factors. FEBS Lett. 419, 249-254 (1997). 
11. Kobe, B. Autoinhibition by an internal nuclear localization signal revealed by the crystal structure of mammalian importin $\alpha$. Nat. Struct. Mol. Biol. 6, 388-397 (1999).

12. Fontes, M. R., Teh, T. \& Kobe, B. Structural basis of recognition of monopartite and bipartite nuclear localization sequences by mammalian importin-a. J. Mol. Biol. 297, 1183-1194 (2000).

13. Chen, M.-H. et al. Phospholipid scramblase 1 contains a nonclassical nuclear localization signal with unique binding site in importin a. J. Biol. Chem. 280, 10599-10606 (2005)

14. Giesecke, A. \& Stewart, M. Novel binding of the mitotic regulator TPX2 (target protein for Xenopus kinesin-like protein 2) to importin-a. J. Biol. Chem. 285, 17628-17635 (2010).

15. Sankhala, R. S. et al. Three-dimensional context rather than NLS amino acid sequence determines importin a subtype specificity for RCC1. Nat. Commun. 8, 979 (2017).

16. Ao, Z. et al. Importin $a 3$ interacts with HIV-1 integrase and contributes to HIV-1 nuclear import and replication. J. Virol. 84, 8650-8663 (2010).

17. $\mathrm{Xu}, \mathrm{W}$. et al. Ebola virus VP24 targets a unique NLS binding site on karyopherin alpha 5 to selectively compete with nuclear import of phosphorylated STAT1. Cell Host. Microbe 16, 187-200 (2014)

18. Nardozzi, J., Wenta, N., Yasuhara, N., Vinkemeier, U. \& Cingolani, G. Molecular basis for the recognition of phosphorylated STAT1 by importin $\alpha 5$. J. Mol. Biol. 402, 83-100 (2010).

19. Pumroy, R. A., Ke, S., Hart, D. J., Zachariae, U. \& Cingolani, G. Molecular determinants for nuclear import of influenza A PB2 by importin $\alpha$ isoforms 3 and 7. Structure 23, 374-384 (2015).

20. Shaw, M. L., Cardenas, W. B., Zamarin, D., Palese, P. \& Basler, C. F. Nuclear localization of the Nipah virus $\mathrm{W}$ protein allows for inhibition of both virusand toll-like receptor 3-triggered signaling pathways. J. Virol. 79, 6078-6088 (2005).

21. Audsley, M. D., Jans, D. A. \& Moseley, G. W. Nucleocytoplasmic trafficking of Nipah virus W protein involves multiple discrete interactions with the nuclear import and export machinery. Biochem. Biophys. Res. Commun. 479, 429-433 (2016).

22. Eaton, B. T., Broder, C. C., Middleton, D. \& Wang, L.-F. Hendra and Nipah viruses: different and dangerous. Nat. Rev. Microbiol. 4, 23-35 (2006).

23. Kulkarni, S. et al. Nipah virus edits its $\mathrm{P}$ gene at high frequency to express the V and W proteins. J. Virol. 83, 3982-3987 (2009).

24. Wang, L.-F. et al. Molecular biology of Hendra and Nipah viruses. Microbes Infect. 3, 279-287 (2001).

25. Lo, M. K. et al. Determination of the henipavirus phosphoprotein gene mRNA editing frequencies and detection of the $\mathrm{C}, \mathrm{V}$ and $\mathrm{W}$ proteins of Nipah virus in virus-infected cells. J. Gen. Virol. 90, 398-404 (2009).

26. Shaw, M. L., García-Sastre, A., Palese, P. \& Basler, C. F. Nipah virus V and W proteins have a common STAT1-binding domain yet inhibit STAT1 activation from the cytoplasmic and nuclear compartments, respectively. J. Virol. 78, 5633-5641 (2004).

27. Satterfield, B. A. et al. The immunomodulating $\mathrm{V}$ and $\mathrm{W}$ proteins of Nipah virus determine disease course. Nat. Commun. 6, 7483 (2015).

28. Satterfield, B. A. et al. The Nipah virus $C$ and $W$ proteins contribute to respiratory disease in ferrets. J. Virol. JVI, 00215-00216 (2016).

29. Yoneda, M. et al. The nonstructural proteins of Nipah virus play a key role in pathogenicity in experimentally infected animals. PLoS ONE 5, e12709 (2010).

30. Lo, M. K. et al. Characterization of the antiviral and inflammatory responses against Nipah virus in endothelial cells and neurons. Virology 404, 78-88 (2010).

31. Martinez-Gil, L., Vera-Velasco, N. M. \& Mingarro, I. Exploring the humanNipah virus protein-protein interactome. J. Virol. 91, e01461-01417 (2017).

32. Ciancanelli, M. J., Volchkova, V. A., Shaw, M. L., Volchkov, V. E. \& Basler, C. F. Nipah virus sequesters inactive STAT1 in the nucleus via a P gene-encoded mechanism. J. Virol. 83, 7828-7841 (2009).

33. Miyatake, $H$. et al. Crystal structure of human importin- $\alpha 1$ (Rch1), revealing a potential autoinhibition mode involving homodimerization. PLOS ONE 10, e0115995 (2015).

34. Welch, K., Franke, J., Kohler, M. \& Macara, I. G. RanBP3 contains an unusual nuclear localization signal that is imported preferentially by importinalpha3. Mol. Cell Biol. 19, 8400-8411 (1999).

35. Fagerlund, R., Kinnunen, L., Kohler, M., Julkunen, I. \& Melen, K. NF-\{kappa\} $\mathrm{B}$ is transported into the nucleus by importin \{alpha\} 3 and importin \{alpha\}4. J. Biol. Chem. 280, 15942-15951 (2005).

36. Reid, S. P., Valmas, C., Martinez, O., Sanchez, F. M. \& Basler, C. F. Ebola virus VP24 proteins inhibit the interaction of NPI-1 subfamily karyopherin alpha proteins with activated STAT1. J. Virol. 81, 13469-13477 (2007).

37. Gabriel, G. et al. Differential use of importin-[alpha] isoforms governs cell tropism and host adaptation of influenza virus. Nat. Commun. 2, 156 (2011).

38. Nardozzi, J. D., Lott, K. \& Cingolani, G. Phosphorylation meets nuclear import: a review. Cell Commun. Signal. 8, 32 (2010).
39. Yasuhara, N. et al. Triggering neural differentiation of ES cells by subtype switching of importin-alpha. Nat. Cell Biol. 9, 72-79 (2007).

40. Yasuhara, N. \& Yoneda, Y. Importins in the maintenance and lineage commitment of ES cells. Neurochem. Int. (2017).

41. Venugopal, A. K. et al. Quantitative proteomics for identifying biomarkers for Rabies. Clin. Proteom. 10, 3 (2013).

42. Yang, J. et al. Inhibition of KPNA4 attenuates prostate cancer metastasis. Oncogene 36, 2868-2878 (2017).

43. Teh, T., Tiganis, T. \& Kobe, B. Crystallization of importin $\alpha$, the nuclearimport receptor. Acta Crystallogr. D Biol. Crystallogr. 55, 561-563 (1999).

44. Marfori, M. et al. Molecular basis for specificity of nuclear import and prediction of nuclear localization. Biochim. Et. Biophys. Acta 1813, 1562-1577 (2011).

45. Studier, F. W. Protein production by auto-induction in high-density shaking cultures. Protein Expr. Purif. 41, 207-234 (2005).

46. Smith, K. M. et al. Contribution of the residue at position 4 within classical nuclear localization signals to modulating interaction with importins and nuclear targeting. Biochim. Biophys. Acta 1865, 1114-1129 (2018).

47. Chaston, J. J., Stewart, A. G. \& Christie, M. Structural characterisation of TNRC6A nuclear localisation signal in complex with importin-alpha. PLoS ONE 12, e0183587 (2017)

48. da Costa, T. P. S. et al. Structural determinants defining the allosteric inhibition of an essential antibiotic target. Structure 24, 1282-1291 (2016).

49. Cowieson, N. P. et al. MX1: a bending-magnet crystallography beamline serving both chemical and macromolecular crystallography communities at the Australian Synchrotron. J. Synchrotron Radiat. 22, 187-190 (2015).

50. Aragão, D. et al. MX2: a high-flux undulator microfocus beamline serving both the chemical and macromolecular crystallography communities at the Australian Synchrotron. Synchrotron Radiat. 25, 885-891 (2018).

51. Battye, T. G. G., Kontogiannis, L., Johnson, O., Powell, H. R. \& Leslie, A. G. W. iMOSFLM: a new graphical interface for diffraction-image processing with MOSFLM. Acta Crystallogr. D Biol. Crystallogr. 67, 271-281 (2011).

52. Kabsch, W. XDS. Acta Crystallogr. D Biol. Crystallogr. 66, 125-132 (2010).

53. Evans, P. R. An introduction to data reduction: space-group determination, scaling and intensity statistics. Acta Crystallogr. D Biol. Crystallogr. 67 282-292 (2011)

54. Evans, P. Scaling and assessment of data quality. Acta Crystallogr. D Biol. Crystallogr. 62, 72-82 (2006).

55. Winn, M. D. et al. Overview of the CCP4 suite and current developments. Acta Crystallogr. D Biol. Crystallogr. 67, 235-242 (2011).

56. McCoy, A. J. et al. Phaser crystallographic software. J. Appl. Crystallogr. 40, 658-674 (2007).

57. Emsley, P., Lohkamp, B., Scott, W. G. \& Cowtan, K. Features and development of Coot. Acta Crystallogr. D Biol. Crystallogr. 66, 486-501 (2010).

58. Adams, P. D. et al. PHENIX: a comprehensive python-based system for macromolecular structure solution. Acta Crystallogr. D Biol. Crystallogr. 66, 213-221 (2010).

59. Kosugi, S. et al. Design of peptide inhibitors for the importin $\alpha / \beta$ nuclear import pathway by activity-based profiling. Chem. Biol. 15, 940-949 (2008).

60. Marfori, M., Lonhienne, T. G., Forwood, J. K. \& Kobe, B. Structural basis of high-affinity nuclear localization signal interactions with importin - $a$. Traffic 13, 532-548 (2012)

61. Dias, S. M., Wilson, K. F., Rojas, K. S., Ambrosio, A. L. \& Cerione, R. A. The molecular basis for the regulation of the cap-binding complex by the importins. Nat. Struct. Mol. Biol. 16, 930-937 (2009).

62. Koyama, M. \& Matsuura, Y. Crystal structure of importin- $\alpha 3$ bound to the nuclear localization signal of Ran-binding protein 3. Biochem. Biophys. Res. Commun. 491, 609-613 (2017).

\section{Acknowledgements}

Funding from NIH grants U19AI109664 and U19AI109945 assisted this work. This research was undertaken in part using the MX2 beamline at the Australian Synchrotron, part of ANSTO, and made use of the Australian Cancer Research Foundation (ACRF) Detector. TPSC is supported by an NHMRC Fellowship (APP1091976). We also acknowledge the La Trobe University-Comprehensive Proteomics Platform for providing infrastructure. CFB is a Georgia Research Alliance Eminent Scholar in Microbial Pathogenesis. ST and EC were supported through a Graham Centre scholarship.

\section{Author contributions}

K.M.S. performed protein expression, purification, crystallisation, structure determination, structure analysis and manuscript preparation, S.T. performed protein expression, purification, crystallisation, structure determination and manuscript preparation, M.R.E. performed cloning, pull-down and nuclear import experiments, and manuscript preparation, J.B. performed cloning, T.P.S.C. performed MST experiments, D.A. assisted with data collection and structure determination, E.M.C. performed protein expression, 
purification, crystallisation, C.F.B. performed experiment design and analysis and manuscript preparation, J.K.F. performed structure determination and manuscript preparation.

\section{Additional information}

Supplementary Information accompanies this paper at https://doi.org/10.1038/s41467018-05928-5.

Competing interests: The authors declare no competing interests.

Reprints and permission information is available online at http://npg.nature.com/ reprintsandpermissions/

Publisher's note: Springer Nature remains neutral with regard to jurisdictional claims in published maps and institutional affiliations. (c) (i) Open Access This article is licensed under a Creative Commons Attribution 4.0 International License, which permits use, sharing, adaptation, distribution and reproduction in any medium or format, as long as you give appropriate credit to the original author(s) and the source, provide a link to the Creative Commons license, and indicate if changes were made. The images or other third party material in this article are included in the article's Creative Commons license, unless indicated otherwise in a credit line to the material. If material is not included in the article's Creative Commons license and your intended use is not permitted by statutory regulation or exceeds the permitted use, you will need to obtain permission directly from the copyright holder. To view a copy of this license, visit http://creativecommons.org/ licenses/by/4.0/.

(C) The Author(s) 2018 